\title{
Muscle injury, impaired muscle function and insulin resistance in Chromogranin A-knockout mice
}

\author{
Kechun Tang1, Teresa Pasqua', Angshuman Biswas', Sumana Mahata², \\ Jennifer Tang', Alisa Tang', Gautam K Bandyopadhyay', Amiya P Sinha-Hikim ${ }^{3,4}$, \\ Nai-Wen Chi1,5, Nicholas J G Webster ${ }^{1,5}$, Angelo Corti ${ }^{6}$ and Sushil K Mahata ${ }^{1,5}$ \\ 1Department of Medicine, University of California, San Diego, La Jolla, California, USA \\ 2Division of Biology \& Biological Engineering, California Institute of Technology, Pasadena, California, USA \\ ${ }^{3}$ Charles Drew University of Medicine and Science, Los Angeles, California, USA \\ ${ }^{4}$ David Geffen School of Medicine, University of California-Los Angeles, Los Angeles, California, USA \\ ${ }^{5}$ VA San Diego Healthcare System, San Diego, California, USA \\ ${ }^{\prime} I R C C S$ San Raffaele Scientific Institute, San Raffaele Vita-Salute University, Milan, Italy
}

Correspondence should be addressed to S K Mahata Email

smahata@ucsd.edu

\begin{abstract}
Chromogranin $\mathrm{A}(\mathrm{CgA})$ is widely expressed in endocrine and neuroendocrine tissues as well as in the central nervous system. We observed CgA expression (mRNA and protein) in the gastrocnemius (GAS) muscle and found that performance of CgA-deficient Chga-KO mice in treadmill exercise was impaired. Supplementation with CgA in Chga-KO mice restored exercise ability suggesting a novel role for endogenous CgA in skeletal muscle function. Chga-KO mice display (i) lack of exercise-induced stimulation of pAKT, pTBC1D1 and phospho-p38 kinase signaling, (ii) loss of GAS muscle mass,

(iii) extensive formation of tubular aggregates (TA), (iv) disorganized cristae architecture in mitochondria, (v) increased expression of the inflammatory cytokines Tnfo, $1 / 6$ and Ifn $\gamma$, and fibrosis. The impaired maximum running speed and endurance in the treadmill exercise in Chga-KO mice correlated with decreased glucose uptake and glycolysis, defects in glucose oxidation and decreased mitochondrial cytochrome $\mathrm{C}$ oxidase activity. The lack of adaptation to endurance training correlated with the lack of stimulation of p38MAPK that is known to mediate the response to tissue damage. As CgA sorts proteins to the regulated secretory pathway, we speculate that lack of CgA could cause misfolding of membrane proteins inducing aggregation of sarcoplasmic reticulum (SR) membranes and formation of tubular aggregates that is observed in Chga-KO mice. In conclusion, $\mathrm{CgA}$ deficiency renders the muscle energy deficient, impairs performance in treadmill exercise and prevents regeneration after exercise-induced tissue damage.
\end{abstract}

Journal of Endocrinology (2017) 232, 137-153

\section{Introduction}

Chromogranin A (CgA), the secretory proprotein of chromaffin granules, is widely expressed in endocrine and neuroendocrine tissues as well as in the central nervous system (Winkler \& Fischer-Colbrie 1992,
Montero-Hadjadje et al. 2008, Bartolomucci et al. 2011). CgA is processed to multiple biologically active peptides including pancreastatin (Tatemoto et al. 1986, SanchezMargalet et al. 2010), vasostatin I (Aardal et al. 1993, 
Tota et al. 2008), catestatin (Mahata et al. 1997, 2003, Mahapatra et al. 2005, Angelone et al. 2008) and serpinin (Tota et al. 2012). The CgA protein was initially detected in the large dense-core vesicles of sympathetic nerves and in the brainstem, which is rich in adrenergic neurons (Banks et al. 1969, De Potter et al. 1970a, Bartlett et al. 1976). Therefore, it was assumed that $\mathrm{CgA}$ is an adrenergic protein confined to the sympathetic nerve (Banks et al. 1969, De Potter et al. 1970b, Bartlett et al. 1976) and to the adrenal medulla (Helle 1966, Smith \& Kirshner 1967, Smith \& Winkler 1967). Subsequently, CgA was also detected in cholinergic motor neurons of the spinal cord (Somogyi et al. 1984) and in cholinergic nerve terminals in the muscles of the diaphragm (Volknandt et al. 1987). These latter findings suggested that CgA might influence skeletal muscle function and indeed $\mathrm{CgA}$-knockout mice display impaired skeletal muscle function in addition to hyperadrenergic (Mahapatra et al. 2005), hypertensive (Mahapatra et al. 2005) and insulin-sensitive phenotypes (Gayen et al. 2009).

During exercise, the muscle's increased need for energy is compensated by increasing uptake and utilization of glucose as the primary energy source (Goodyear \& Kahn 1998). Both exercise and insulin increase glucose uptake in skeletal muscle through the translocation of the Glut4 glucose transporter from an intracellular compartment to the surface of the cell in response to activation of the Rab GTPase TBC1D1 (Douen et al. 1989, Hirshman et al. 1990, Goodyear et al. 1991a,b). Muscle contraction recruits Glut4 to the plasma membrane independently of insulin in rat skeletal muscle, suggesting alternative but convergent signaling (Goodyear et al. 1990). Therefore, a combination of exercise and insulin can exert additive effects on glucose transport.

Exercise injures skeletal muscle by damaging the attachment of myofibrils to the extrasarcolemic cytoskeleton (Friden et al. 1991) and evoking an inflammatory response (Paulsen et al. 2013). A number of intracellular mechanisms contribute to muscle damage including calcium overload, reactive oxygen species (ROS) production and a decrease in cellular ATP (Armstrong et al. 1991). This fall in ATP levels in response to exercise stress (Perrey \& Rupp 2009) activates Pgc1 $\alpha$, AMPK and p38MAPK kinase signaling to allow cells to adapt (Gibala 2009). This post-exercise response involves mitochondrial biogenesis concomitant with the onset of muscle fiber differentiation (Duguez et al. 2002, Gibala 2009). Regeneration of muscle fibers takes place through the activation of quiescent muscle precursor cells, the formation of proliferating progenitor satellite cells leading to fusion into differentiated myofibers (Wagers \& Conboy 2005). The intermediate progenitor cells express MyoD and myogenic transcription factor Pax3 and asymmetrically divide and differentiate into myoblasts expressing Pax3, Myf-5 and desmin (Conboy $\&$ Rando 2002). The activation of satellite cells under the basal lamina of muscle fibers is accelerated by insulin-like growth factor-I and mechano-growth factor induced in exhausted muscles after training (Machida \& Booth 2004, Schiaffino \& Mammucari 2011).

Exercise-induced muscle pain, stiffness and cramping are caused by enzyme deficiencies such as myophosphorylase deficiency and phosphofructokinase deficiency leading to metabolic defects (Tarui et al. 1965, Layzer et al. 1967, Cornelio \& Di Donato 1985). Both deficiencies are accompanied by reduced anaerobic glycolysis resulting in reduced levels of muscle lactate production, higher serum creatine phosphokinase levels and the presence of histological tubular aggregates (TA) in type-II muscle fibers (Bertorini et al. 1977, KorenyiBoth et al. 1977). TAs are ordered arrays of cylindrical sarcoplasmic reticulum (SR) tubules that are observed in many skeletal muscle myopathies (Boncompagni et al. 2012). Experimental inhibition of glycolysis with iodoacetate produces a similar muscle phenotype (Brumback et al. 1980), and these TAs have been found in other experimental models including extreme hypoxia in rats (Schiaffino et al. 1977) and the deficiency of dystrophin (Craig \& Allen 1980) or Caveolin-1 or -2 (Schubert et al. 2007) in mice. The formation of TAs in injured muscle fibers may be associated with exercise-induced muscle pain (Brumback et al. 1981). Accumulation of calsequestrin, a sarcoplasmic reticulum (SR) $\mathrm{Ca}^{2+}$-binding protein, triggers TA formation through swelling of free SR cisternae and extension of the enlarged SR sacs into multiple, longitudinally oriented tubules with SERCA (sarcoplasmic reticulum $\mathrm{Ca}^{2+}$ ATPases) in the membrane and calsequestrin in the lumen (Boncompagni et al. 2012).

We have previously shown hepatic insulin sensitivity but muscular insulin resistance in Chga-KO mice (Gayen et al. 2009). Here, we show impaired muscle function, muscle fiber degeneration and decreased insulin signaling coupled with attenuated glucose uptake and metabolism in Chga-KO skeletal muscle. In addition, at the ultrastructural level, we found the presence of TAs in gastrocnemius (GAS) muscle of Chga-KO mice. Treatment of Chga-KO mice with CgA for 15 days restored muscle performance, which establishes a novel role of $\mathrm{CgA}$ in the regulation of skeletal muscle function.

Published by Bioscientifica Ltd 


\section{Materials and methods}

\section{Animals}

Adult (5-6 months old) male Chga-KO mice on a mixed genetic background (50\% 129svJ; 50\% C57BL/6J) and wildtype C57BL/6J mice were studied. Mice were kept on a 12-h darkness/light cycle and fed ad libitum with a normal chow diet (NCD: 14\% calories from fat; LabDiet 5P00). The Institutional Animal Care and Use Committee of the University of California San Diego approved all procedures.

\section{Immunoblotting}

Tissues were homogenized in a lysis buffer containing phosphatase and protease inhibitors. Homogenates were subjected to $10 \%$ SDS-PAGE and immunoblotted. The following primary antibodies were obtained from Cell Signaling Technology: AKT and pS473-AKT (rabbit polyclonal at 1:1000 dilution), AMPK and pT172-AMPK $\alpha$ (rabbit polyclonal at 1:1000 dilution), P38 and pT180/ Y182-P38 (rabbit polyclonal at 1:1000 dilution), TBC1D1, pT590-TBC1D1 and pS700-TBC1D1 (rabbit polyclonal at 1:500 dilation). Anti-CgA (hCgA $\left.\mathrm{h}_{352-372}\right)$ polyclonal antibody was raised in rabbit by a commercial vendor Sdix Inc. (Newark, DE, USA) and used at a dilution of 1:1000. This antibody detected full-length CgA $(75 \mathrm{kDa})$, proteoglycan form of $\mathrm{CgA}(90 \mathrm{kDa})$ and proteolytically processed $\mathrm{CgA}(49 \mathrm{kDa}$ and $30 \mathrm{kDa})$. In addition, we also used anti-CgA mouse monoclonal antibody 5A8 (epitope $\mathrm{hCgA}_{\mathrm{R} 4-\mathrm{L} 57}$ ) (Ratti et al. 2000) at a dilution of 1:1000 that cross-reacts with murine CgA (Colombo et al. 2002).

\section{Real-time RT-PCR assay for the measurement of target mRNAs}

Total cellular RNA from GAS was isolated with TriPure Isolation Reagent (Invitrogen) and purified, and DNase I was treated with RNAeasy Mini Kit (Qiagen). Either a Thermoscript kit (Invitrogen) or a qScript CDNA synthesis kit (Quantabio, Beverly, MA, USA) was used for reverse transcription from total RNA. The RT products were amplified either with an RT2 Real-Time SYBR Green Kit (AuperArray, Fredrick, MD, USA) or PERFECTA SYBR FASTMIX L-ROX 1250 (Quantabio). PCR reactions were run either on a MxP3000 Real-Time PCR system (Stratagene) or an Applied Biosystems 7500 Fast RealTime PCR system. All PCRs were normalized to Gapdh, and relative expression levels were determined by the $\Delta \Delta C_{t}$ method. Primer sequences are provided in Table 1.

\section{2-deoxy-glucose (2DG) uptake and glucose metabolism}

In vivo glucose uptake and production of glucose6-phosphate (G6P) were carried out essentially as described by Crosson et al. (2003) but using double isotopes ${ }^{3} \mathrm{H}$-glucose and ${ }^{14} \mathrm{C}$-2-deoxyglucose (2DG).

Table 1 Primer sequences for genes used in the real-time PCR analysis.

\begin{tabular}{|c|c|}
\hline Description & Sequence $5^{\prime}-3^{\prime}$ \\
\hline Acta2/a-Sma-FP & TCCCAGACATCAGGGAGTAA \\
\hline Acta2/a-Sma-RP & TCGGATACTTCAGCGTCAGGA \\
\hline Cd36-FP & ATGGGCTGTGATCGGAACTG \\
\hline Cd36-RP & GTCTTCCCAATAAGCATGTCTCC \\
\hline Chga-FP & CCAAGGTGATGAAGTGCGTC \\
\hline Chga-RP & GGTGTCGCAGGATAGAGAGGA \\
\hline Chgb-FP & AGCTCCAGTGGATAACAGGGA \\
\hline Chgb-RP & GATAGGGCATTTGAGAGGACTTC \\
\hline Col1a1-FP & GTGCTCCTGGTATTGCTGGT \\
\hline Col1a1-RP & GGCTCCTCGTTTTTCCTTCTT \\
\hline Col3a1-FP & GGGTTTCCCTGGTCCTAAAG \\
\hline Col3a1-RP & СCTGGTTTCCCATTTTCTCC \\
\hline Fn1-FP & TTGAGGAACATGGCTTTAGGC \\
\hline Fn1-RP & CTGGGAACATGACCGATTTG \\
\hline Fbx032/Atrogin1-FP & CAGCTTCGTGAGCGACCTC \\
\hline Fbx032/Atrogin1-RP & GGCAGTCGAGAAGTCCAGTC \\
\hline Gapdh-FP & AGGTCGGTGTGAACGGATTTG \\
\hline Gapdh-RP & TGTAGACCATGTAGTTGAGGTCA \\
\hline Slc2a4/Glut4-FP & ACACTGGTCCTAGCTGTATTCT \\
\hline S/c2a4/Glut4-RP & CCAGCCACGTTGCATTGTA \\
\hline Ifng-FP & ATGAACGCTACACACTGCATC \\
\hline Ifng-RP & CCATCCTTTTGGCCAGTTCCTC \\
\hline$/ / 1 b-\mathrm{FP}$ & GCAACTGTTCCTGAACTCAACT \\
\hline$/ / 1 b-\mathrm{RP}$ & ATCTTTTGGGGTCCGTCAACT \\
\hline //6-FP & TAGTCCTTCCTACCCCAATTTCC \\
\hline I/6-RP & TTGGTCCTTAGCCACTCCTTC \\
\hline //10-FP & GCTCTTACTGACTGGCATGAG \\
\hline //10-RP & CGCAGCTCTAGGAGCATGTG \\
\hline Lox-FP & TCCGCAAAGAGTGAAGAACC \\
\hline Lox-RP & CATCAAGCAGGTCATAGTGG \\
\hline Myf5-FP & AAGGCTCCTGTATCCCCTCAC \\
\hline Myf5-RP & TGACCTTCTTCAGGCGTCTAC \\
\hline Nes-FP & CCCTGAAGTCGAGGAGCTG \\
\hline Nes-RP & CTGCTGCACCTCTAAGCGA \\
\hline Myod1-FP & CCACTCCGGGACATAGACTTG \\
\hline Myod1-RP & AAAAGCGCAGGTCTGGTGAG \\
\hline Myog-FP & GAGACATCCCCCTATTTCTACCA \\
\hline Myog-RP & GCTCAGTCCGCTCATAGCC \\
\hline Pax3-F & CCGGGGCAGAATTACCCAC \\
\hline Pax3-RP & GCCGTTGATAAATACTCCTCCG \\
\hline Pax7-FP & TCTCCAAGATTCTGTGCCGAT \\
\hline Pax7-RP & CGGGGTTCTCTCTCTTATACTCC \\
\hline Scg2-FP & GGAGCTAAGGCGTACCGAC \\
\hline Scg2-RP & TGGACATTCTCCAATCTGAGGT \\
\hline Tnf-FP & СССTCACACTCAGATCATCTTCT \\
\hline Tnf-RP & GCTACGACGTGGGCTACAG \\
\hline Trim63/Murf1-FP & GTGTGAGGTGCCTACTTGCTC \\
\hline Trim63/Murf1-RP & GCTCAGTCTTCTGTCCTTGGA \\
\hline Vegfa-FP & CTGCCGTCCGATTGAGACC \\
\hline Vegfa-RP & ССССTССTTGTACСАСTGTC \\
\hline
\end{tabular}

Published by Bioscientifica Ltd. 
To evaluate glucose uptake in GAS and formation of G6P in vivo, we injected a cocktail of ${ }^{3} \mathrm{H}$-glucose and ${ }^{14} \mathrm{C}-2 \mathrm{DG}$ in $25 \%$ glucose solutions into sedentary WT and Chga-KO mice and looked at the uptake and metabolism after 90 min of injection. As some glucose is trapped in extracellular and interstitial space, which may give an overestimation of uptake, we estimated the contribution of extracellular space to the uptake in each tissue by ${ }^{14} \mathrm{C}$-mannitol incorporation. Blood glucose was measured at 0 and $90 \mathrm{~min}$ after glucose injection. Mice were then killed, and tissues were dissected and frozen rapidly in liquid nitrogen. We determined ${ }^{3} \mathrm{H}$-glucoseand ${ }^{14} \mathrm{C}-2 \mathrm{DG}$-specific activities in blood samples. Tissue homogenates were deproteinized and neutralized, and then the radioactivity in the supernatants was counted before and after passing through an anion exchange resin to remove 2-DG-6-phosphate (2DG6P) and G6P. The difference in radioactivity before and after resin treatment represents the amount of 2DG6P and G6P formed. We counted both ${ }^{3} \mathrm{H}$ and ${ }^{14} \mathrm{C}$. We expect that
A

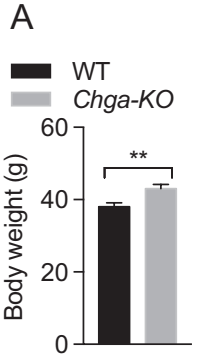

B

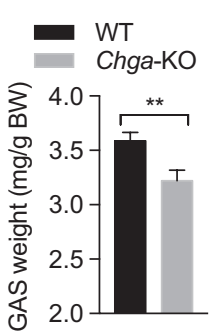

C

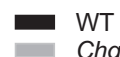

Chga-KO

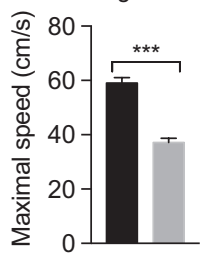

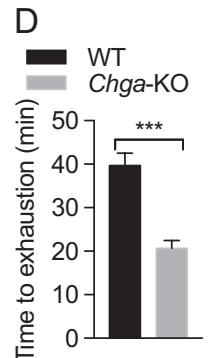
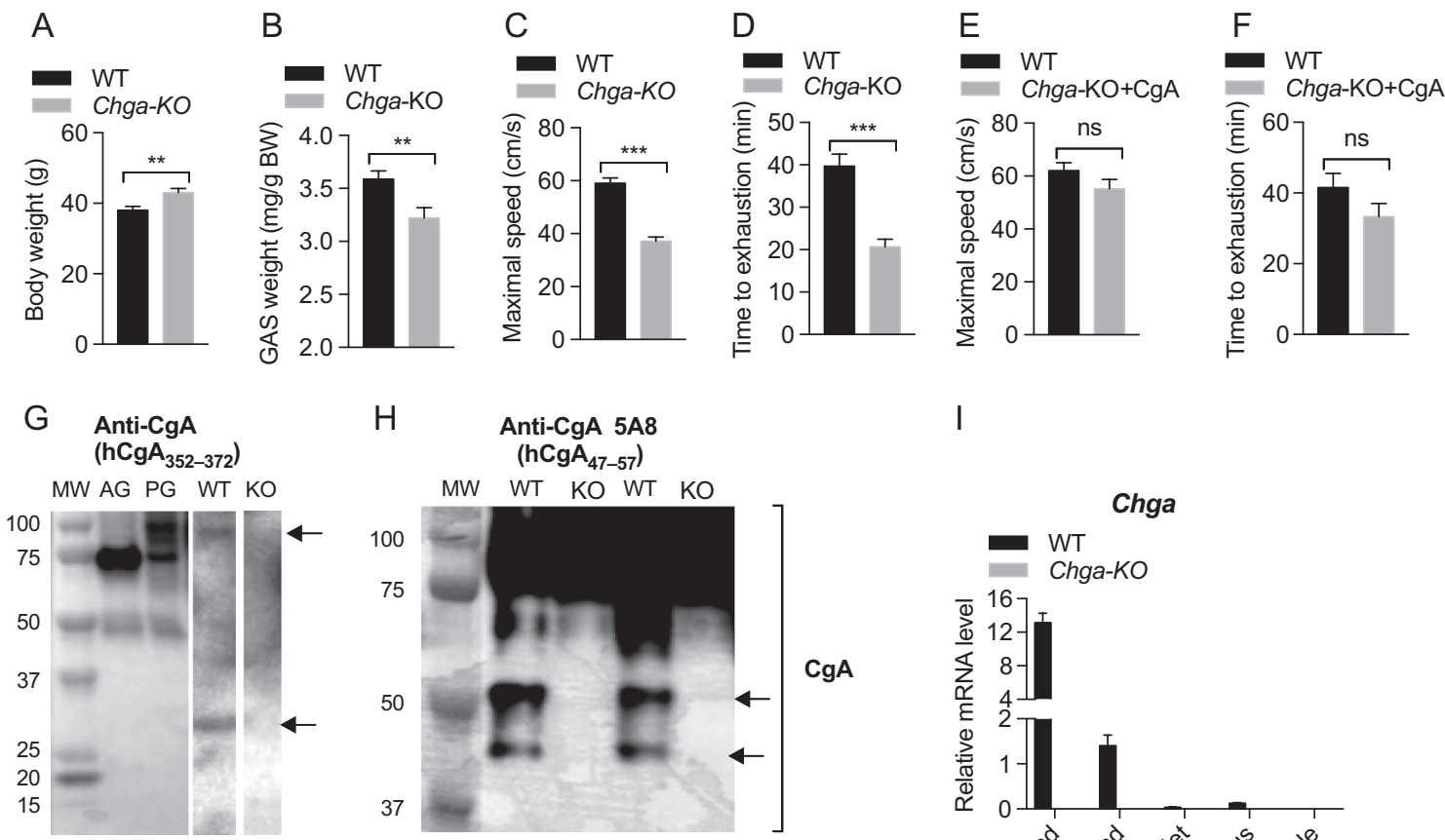

$\mathrm{H} \quad$ Anti-CgA 5A8

(hCgA 47-57)

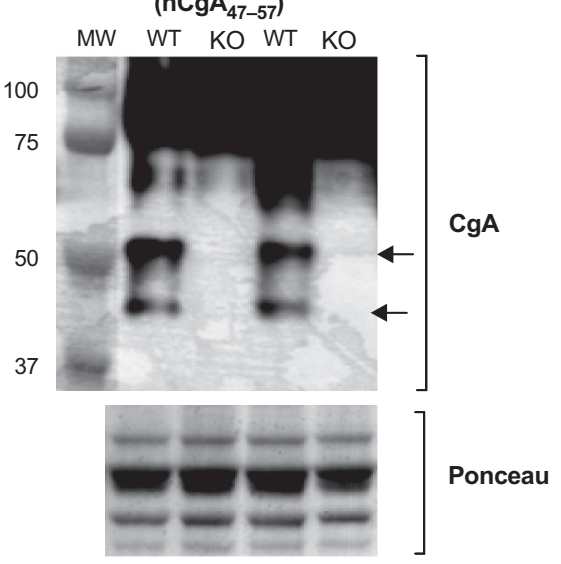

,

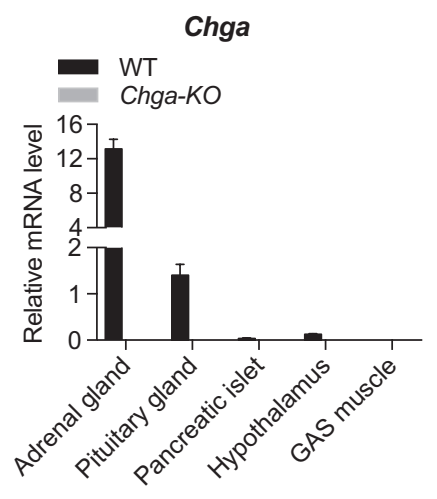

$J$

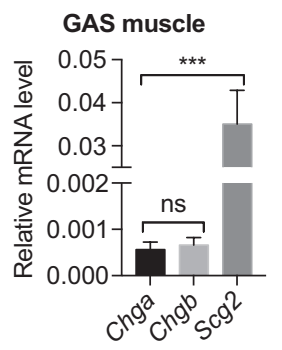

K

Adrenal gland

L
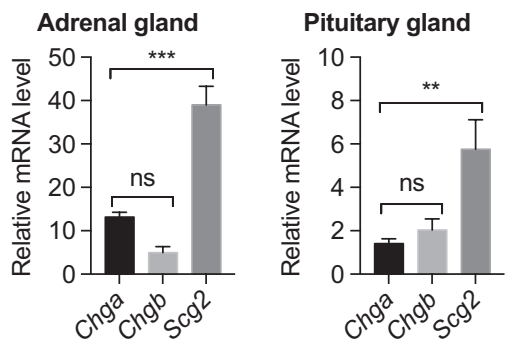

M

Hypothalamus

$\mathrm{N}$

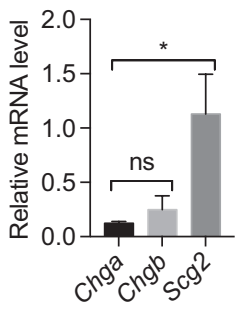

Pancreatic islet

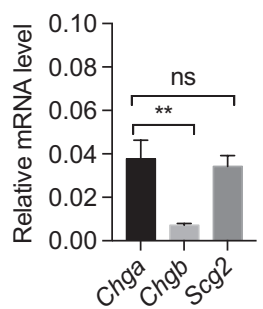

Figure 1

Impaired endurance capacity in Chga-KO mice. (A) Increased body weight in Chga-KO mice. (B) GAS muscle weight is decreased in Chga-KO mice. (C) The $\mathrm{V}_{\mathrm{O} 2}$ maximal speed in an incremental treadmill running test in WT and Chga-KO mice. (D) Endurance exercise capacity was evaluated by the time to reach exhaustion when mice were run at $60 \%$ of the average $\mathrm{V}_{\mathrm{O} 2}$ maximal speed. Supplementation of Chga-KO mice with $\mathrm{CgA}$ for 15 days restored endurance capacity. (E) Maximal speed. (F) Endurance exercise capacity. Expressions of CgA/Chga in GAS muscle. (G and H) Western blot showing expression of CgA in GAS muscle in WT mice and no expression in Chga-KO (KO) mice. (I) Expression of Chga in WT and Chga-KO mice. Expressions of Chga, Chgb and Scg2 genes in GAS muscle (J), adrenal gland (K), pituitary gland (L), hypothalamus (M) and pancreatic islets (N).

http://joe.endocrinology-journals.org DOI: 10.1530/JOE-16-0370
๑) 2017 Society for Endocrinology Printed in Great Britain
Published by Bioscientifica Ltd. 
${ }^{14} \mathrm{C}$ will represent $2 \mathrm{DG}$ uptake, and ${ }^{3} \mathrm{H}$ counts will represent glucose uptake as well as the extent of further metabolism (glycolysis and oxidation) and glycogen formation. Glucose metabolism was determined by the difference of 2DG6P and G6P. For treadmill endurance exercises, mice were run at a speed of $22 \mathrm{~m} / \mathrm{min}$ for 20 min per day for 15 days followed by immediate injection with ${ }^{3} \mathrm{H}$-glucose and ${ }^{14} \mathrm{C}-2 \mathrm{DG}$ in $25 \%$ glucose solutions for the determination of 2DG uptake and metabolism 90 min after glucose injection.

\section{Palmitate uptake and metabolism}

To determine the uptake of palmitic acid in GAS in vivo and formation of acid-soluble metabolite (ASM), we injected $100 \mu \mathrm{L}$ solution of U-14C-palmitic acid-BSA complex (molar ratio 2.5:1), containing $1 \mu \mathrm{Ci}$ and $250 \mu \mathrm{M}$ palmitate, into sedentary WT and ChgaKO mice, and looked at the uptake and metabolism after $90 \mathrm{~min}$ of injection. For treadmill endurance exercise, mice were run at a speed of $22 \mathrm{~m} / \mathrm{min}$ for 20 min per day for 15 days followed by immediate injection of $100 \mu \mathrm{L}$ solution of $\mathrm{U}^{-14} \mathrm{C}$-palmitic acidBSA complex. After $90 \mathrm{~min}$, mice were killed, blood was saved and tissues were put into a mixture of chloroform:methanol:water (1:2:0.8 vol/vol). Tissues were homogenized and centrifuged $(10,000 \boldsymbol{g}$ for $10 \mathrm{~min})$. The pellets were used for protein assay after dissolving in $2 \mathrm{~N} \mathrm{NaOH}$ at $60^{\circ} \mathrm{C}$ for $1 \mathrm{~h}$. To the supernatants, $0.25 \mathrm{~mL}$ chloroform and $0.5 \mathrm{~mL} 1 \mathrm{M} \mathrm{NaCl}$ in $1 \mathrm{M} \mathrm{HCl}$ were added, and the mixtures were vortexed vigorously and centrifuged $(10,000 \boldsymbol{g}, 10 \mathrm{~min})$ to separate two clear layers. The lower chloroform layers containing all lipids were collected in scintillation vials, dried overnight and counted. This radioactivity represents the amount of fatty acids taken up by the tissue. Fatty acid concentration and radioactivity in the saved serum were determined to calculate the specific activity of the radioactive fatty acid in serum. Oxidation of radioactive fatty acids is represented by the radioactivity in $\mathrm{CO}_{2}$ formed and by the radioactivity in the acid-soluble materials (ASM) in the acidified supernatants. We only measured ASM for this work (did not measure ${ }^{14} \mathrm{CO}_{2}$ formation). The upper acidic aqueous layers were neutralized and counted.

\section{Endurance tests}

WT and Chga-KO mice were exercised on an Omnipacer Treadmill LC4 (Omnitech Electronics,
Inc., Columbus, $\mathrm{OH}, \mathrm{USA}$ ) on a $10^{\circ}$ incline while breathing room air. Subjecting mice to an incremental speed running test determined the maximal running capacity. Thus, mice were initially exercised at a speed of $24 \mathrm{~m} / \mathrm{min}$ with increments of $2 \mathrm{~m} / \mathrm{min}$ every $30 \mathrm{~s}$ until exhaustion. To determine endurance capacity, mice were run on a treadmill at $20 \mathrm{~m} / \mathrm{min}$ (60\% of the average maximal speed of Chga-KO mice) at $10^{\circ}$ inclination until exhaustion, which was defined as consistent refusal to run despite contact with the electrical grid at the rear of the treadmill. To find out the role of $\mathrm{CgA}$ in endurance exercise, Chga-KO mice were supplemented with recombinant CgA $(0.05 \mu \mathrm{g} / \mathrm{g}$ BW, IP daily for 15 days) and tested their abilities in endurance exercise. Full-length human CgA1-439 was prepared by recombinant DNA technology in Angelo Corti's laboratory as described previously (Crippa et al. 2013).

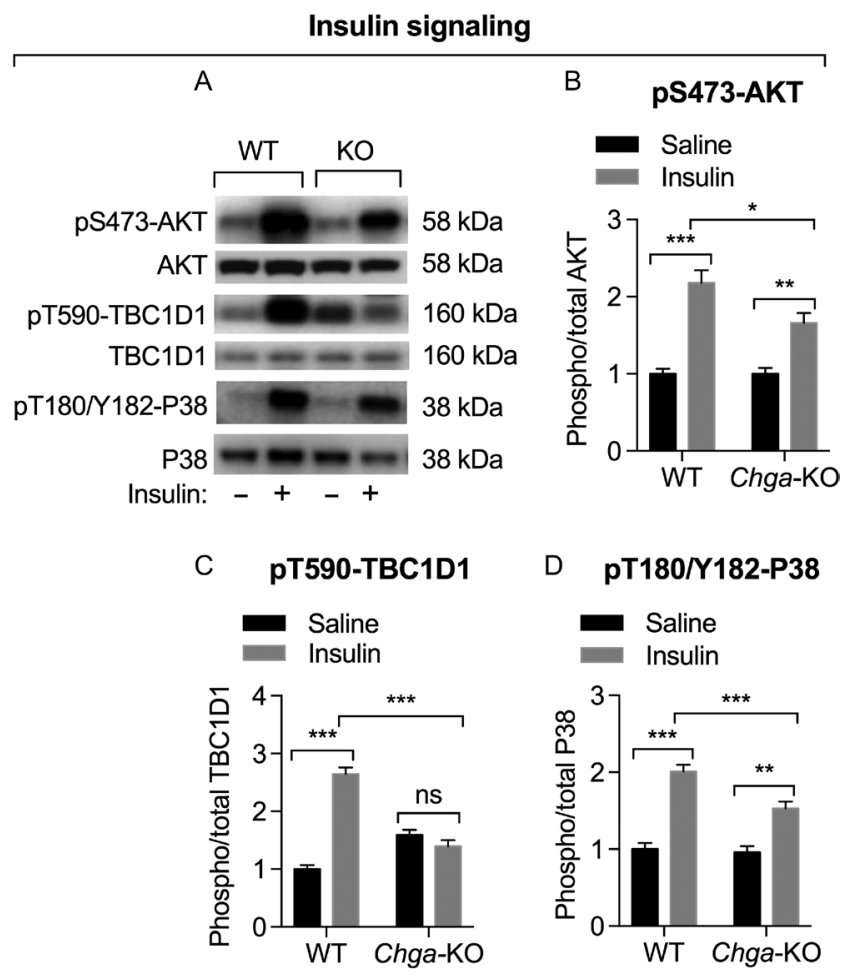

Figure 2

Assessment of insulin-induced signaling by Western blot in GAS muscle. Mice were treated with saline or insulin $(0.4 \mathrm{U} / \mathrm{g} \mathrm{BW})$ for $10 \mathrm{~min}$ before tissue harvesting. (A) Western blots showing the expression of phosphoAKT at Ser473, total AKT, phospho-TBC1D1 at Thr590, total PBC1D1, phospho-P38 at Thr180/Tyr182 and total P38 in WT and Chga-KO mice. Densitometric values showing pS473-AKT/total AKT (B), pT590-TBC1D1/ total TBC1D1 (C), and PT180/Y182-P38/total P38 in WT and Chga-KO mice after endurance exercise. Note compromised insulin-induced signaling in Chga-KO mice.

Published by Bioscientifica Ltd 
Exercise signaling

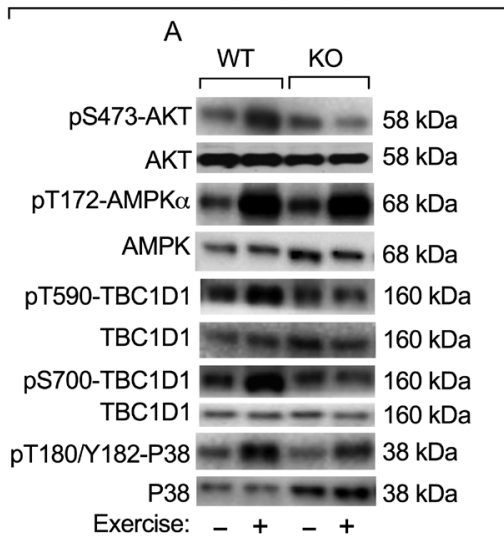

B

pS473-AKT
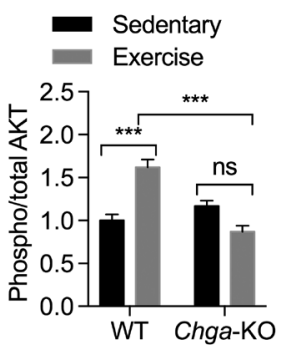

C

\section{PT172-AMPK $\alpha$}

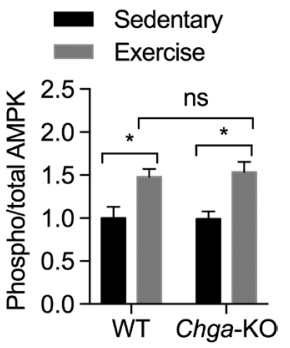

Exercise: - + +
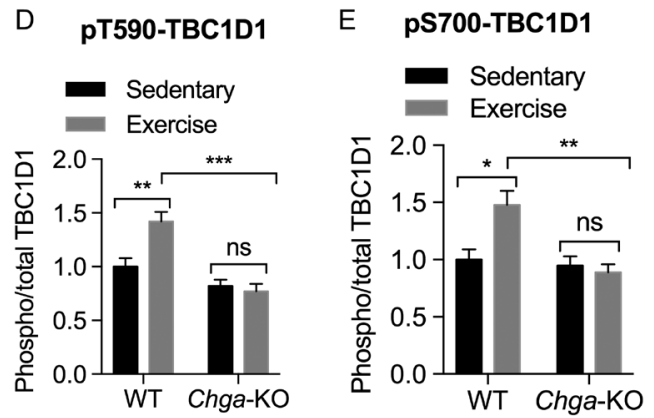

F

pT180/Y182-P38

Sedentary Exercise

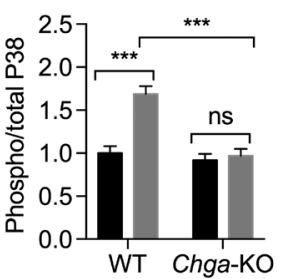

Figure 3

Evaluation of exercise-induced signaling by Western blot in WT and Chga-KO GAS muscle. Mice were treated with saline or insulin $(0.4 \mathrm{U} / \mathrm{g}$ BW) for $10 \mathrm{~min}$ before tissue harvesting. (A) Western blots showing the expression of phospho-AKT at Ser473, total AKT, AMPK $\alpha$ at Thr172, total AMPK, phospho-TBC1D1 at Thr590, phospho-TBC1D1 at Ser700, total PBC1D1, phospho-P38 at Thr180/Tyr182 and total P38 in WT and KO mice. Densitometric values showing pS473-AKT/AKT (B), pT172-AMPK $/$ /AMPK (C), pT590-TBC1D1/TBC1D1 (D), pS700-TBC1D1/ TBC1D1 (E) and PT180/Y182-P38/P38 (F). Note compromised exercise-induced signaling in Chga-KO mice.

\section{Light and transmission electron microscopy (TEM)}

Mice were deeply anesthetized, and the GAS muscles were perfusion fixed through the left ventricle. Mice were flushed with a pre-warmed $\left(37^{\circ} \mathrm{C}\right)$ calcium- and magnesium-free buffer, which is composed of DPBS

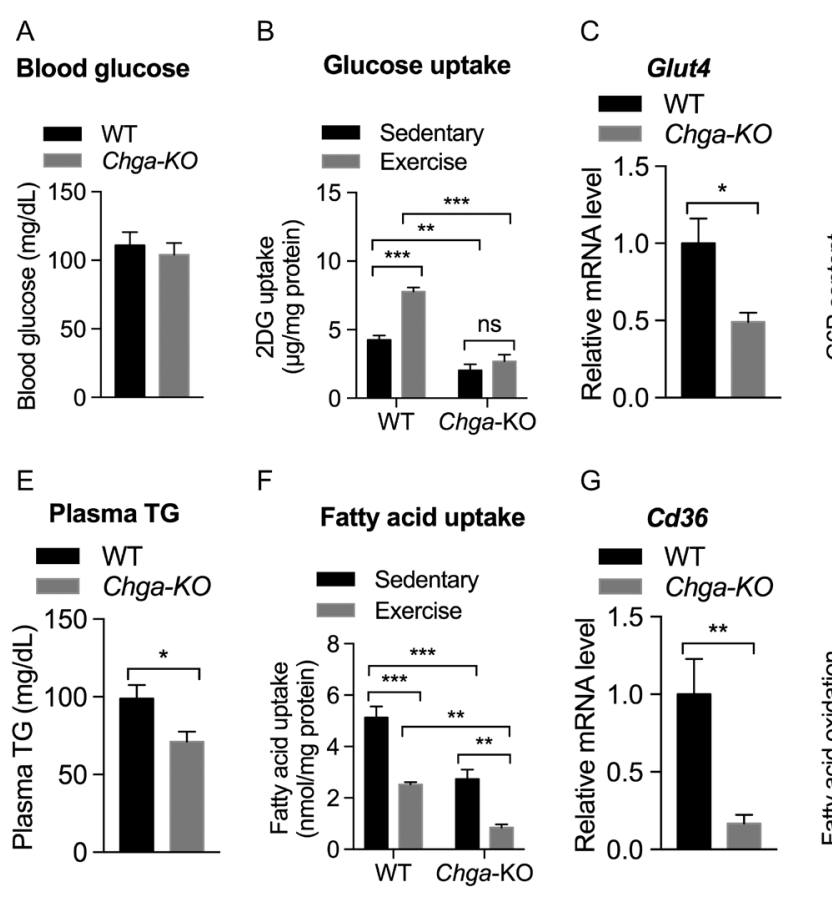

http://joe.endocrinology-journals.org DOI: 10.1530/JOE-16-0370
(Life Technologies), 10mM HEPES, 0.2 mM EGTA, 0.2\% bovine serum albumin, $5 \mathrm{mM}$ glucose and $10 \mathrm{mM} \mathrm{KCl}$ for 3 min followed by perfusion with freshly prepared prewarmed $\left(37^{\circ} \mathrm{C}\right)$ fixative containing $2.5 \%$ glutaraldehyde,
D

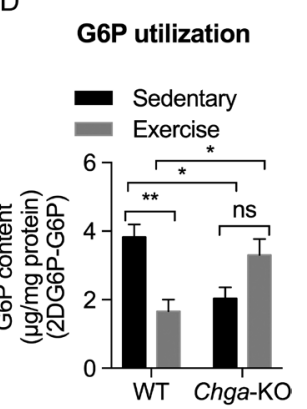

$\mathrm{H}$

\section{Fatty acid oxidation}

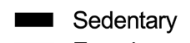

Exercise

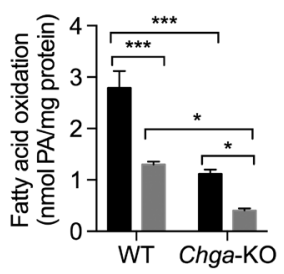

\section{Figure 4}

Substrate uptake and metabolism in sedentary and exercised WT and Chga-KO GAS muscle. (A) Blood glucose. (B) 2-deoxy glucose (2DG) uptake. (C) Glut4 mRNA level. (D) Plasma triglyceride (TG). (E) Utilization of glucose-6-phosphate (G6P). Note low G6P content is an indication of increased G6P utilization. (F) Fatty acid (palmitic acid) uptake. (G) Expression of $\mathrm{Cd} 36$ gene. (H) Fatty acid oxidation (as evaluated by the amount of acid soluble metabolites). Note low values indicate decreased fatty acid oxidation. 
$2 \%$ paraformaldehyde in $0.15 \mathrm{M}$ cacodylate buffer for $3 \mathrm{~min}$ using a peristaltic pump $(5 \mathrm{~mL} / \mathrm{min}$; Langer Instruments Corp, Boonton, NJ, USA). GAS muscles were dissected out and put in the same fixative overnight $(2 \mathrm{~h}$ at room temperature and $12 \mathrm{~h}$ at $4^{\circ} \mathrm{C}$ ), and postfixed in $1 \% \mathrm{OsO}_{4}$ in $0.1 \mathrm{M}$ cacodylate buffer for $1 \mathrm{~h}$ on ice. The tissues were stained en bloc with 2-3\% uranyl acetate for $1 \mathrm{~h}$ on ice. The tissues were dehydrated in graded series of ethanol (20-100\%) on ice followed by one wash with $100 \%$ ethanol and two washes with acetone $(15 \mathrm{~min}$ each) and embedded with Durcupan. Longitudinal and transverse sections were cut at $50-60 \mathrm{~nm}$ on a Leica UCT ultramicrotome and picked up on Formvar- and carboncoated copper grids. Sections were stained with $2 \%$ uranyl acetate for $5 \mathrm{~min}$ and Sato's lead stain for $1 \mathrm{~min}$. Grids were viewed using a JEOL 1200EX II (JEOL, Peabody, MA, USA) TEM and photographed using a Gatan digital camera (Gatan, Pleasanton, CA, USA). Micrographs were randomly taken from 3 GAS each from WT and Chga-KO mice, which were fixed and processed in two different days.

\section{Morphometric analysis}

Samples were blinded and 2 people did measurements randomly from different cells as described previously (Pasqua et al. 2016). The free-hand tool in NIH ImageJ 1.49 software was used to manually trace around the cristae membrane, mitochondrial outer membrane area and cytoplasm area for the determination of the mitochondrial and cristae volume density. The sum of the area of the total complement of cristae represented the cristae membrane surface area. To normalize the measurement, this area was divided by the outer membrane area per mitochondrion. The sum of the area of the mitochondria was divided by the area of the cytoplasm and multiplied by 100 to determine the mitochondrial volume density (\%). For the determination of the cristae volume density (\%), the sum of the area of the cristae was divided by the outer area of the mitochondria and multiplied by 100, as described previously (Pasqua et al. 2016).

\section{Data presentation and statistical analysis}

Data are expressed as mean \pm s.E.M. Statistics was performed with GraphPad Prism 7 software (GraphPad Software). Data were analyzed with one-way ANOVA or 2-way ANOVA followed by multiple comparison tests where appropriate. Additionally, we performed unpaired Student's $t$-tests with Welch's correction when appropriate. Statistical significance was defined as $P<0.05$.

\section{Results}

\section{Loss of CgA impairs muscle performance}

Although Chga-KO mice are 13\% heavier than WT mice (Fig. 1A), the GAS muscle showed a 10\% decrease in weight compared to WT mice (Fig. 1B). Chga-KO mice showed a $37 \%$ decrease in maximum running
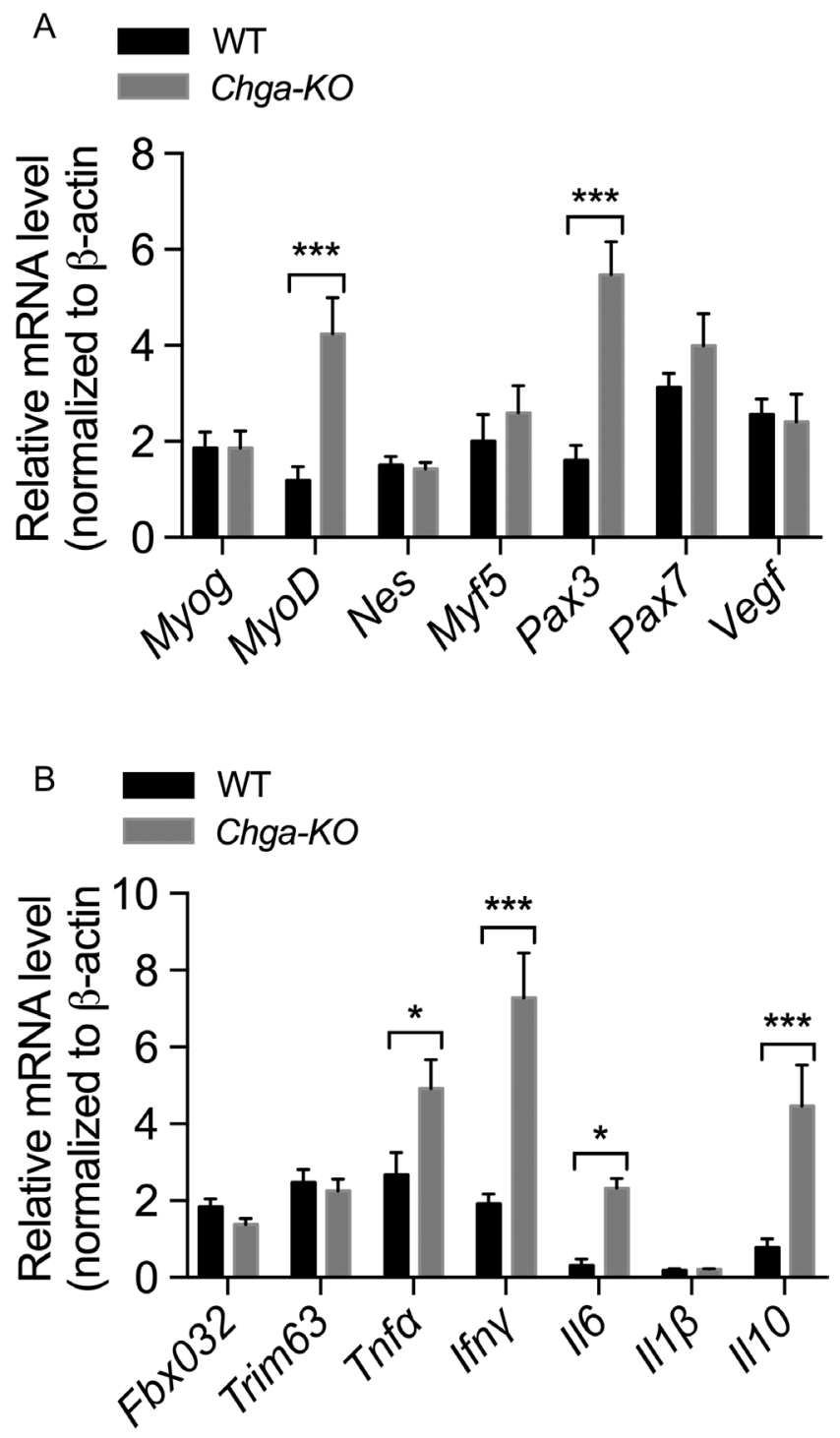

Figure 5

Gene expression in sedentary WT and Chga-KO mice. (A) Relative mRNA levels of myogenin (Myog), myogenic differentiation antigen (MyoD), nestin (Nes), myogenic factor 5 (Myf5), paired box gene 3 (Pax3), paired box gene 7 ( $P a x 7)$ and vascular endothelial growth factor (Vegf) genes. (B) Relative mRNA levels of F-box only protein 32 (Fboxo32/Atrogin1), ring finger protein 28 (Trim63/Murf1), tumor necrosis factor alpha (Tnfo), interferon, gamma $(/ f n \gamma)$, interleukin $6(/ / 6)$, interleukin 1 beta (I1 $\beta$-interleukin 10 (//10) genes. Statistical analyses were made by multiple $t$ tests using Holm-Sidak's correction method.

Published by Bioscientifica Ltd. 
speed compared to WT mice (Fig. 1C) and also showed $48 \%$ decrease in endurance as measured by time to exhaustion (Fig. 1D). We then tested whether supplementation of CgA to Chga-KO mice would restore muscle function. We found that CgA supplementation restored both maximal capacity (Fig. 1E) and endurance performance (Fig. 1F) in Chga-KO mice, indicating an important role for $\mathrm{CgA}$ in skeletal muscle function. With the profound effect on exercise performance and muscle mass, we wondered whether CgA is expressed in GAS muscle. Western blot analyses with a $\mathrm{CgA}$ antiserum ( $\left.\mathrm{hCgA}_{352-372}\right)$ confirmed $\mathrm{CgA}$ expression in GAS muscle (Fig. 1D). As positive controls, we used adrenal and pituitary glands, which showed major bands at 75 and $100 \mathrm{kDa}$, respectively. Like the pituitary gland, GAS muscle showed a CgA proteoglycan band at $100 \mathrm{kDa}$. In addition, adrenal and pituitary glands showed a proteolytically processed band at $49 \mathrm{kDa}$ but GAS muscle showed a $30 \mathrm{kDa}$ fragment (Fig. 1G). Western blot analyses with anti-CgA mouse monoclonal antibody 5A8 (epitope $\mathrm{hCgA}_{47-57}$ ) (Ratti et al. 2000) capable of cross-reacting with murine CgA (Colombo et al. 2002) confirmed CgA expression in GAS muscle (Fig. 1H). Both CgA protein (Fig. 1H) and Chga mRNA (Fig. 1I) were undetectable in Chga-KO mice. We have also detected Chga mRNA in GAS muscle (Fig. 1J). Among the tissues tested (GAS muscle, adrenal gland, pituitary gland, hypothalamus and pancreatic islets),
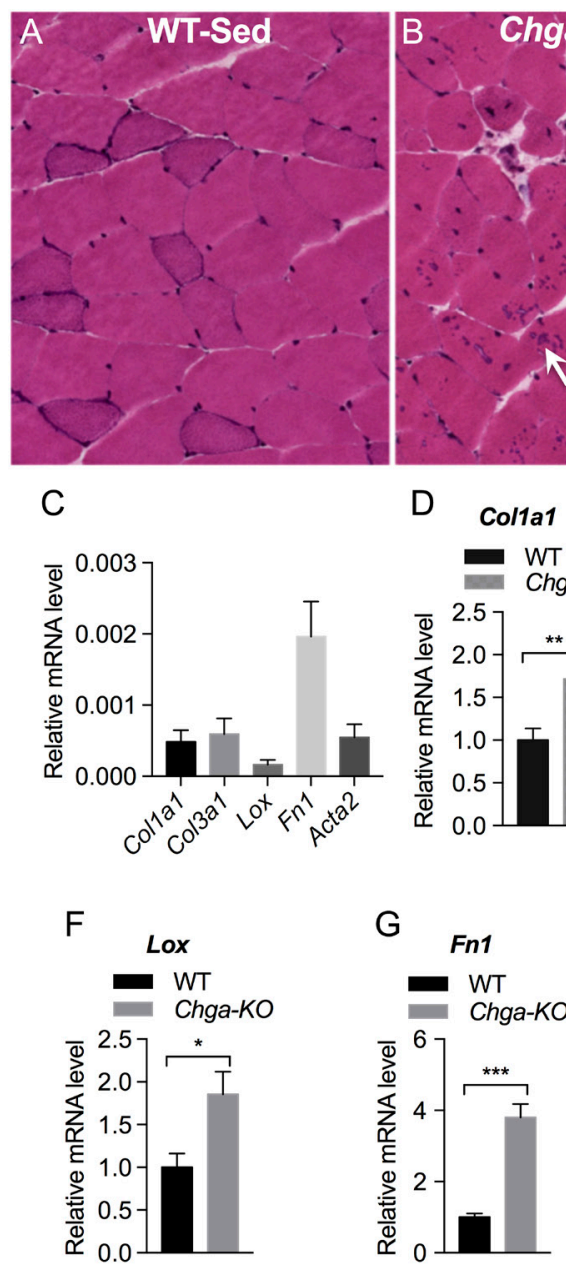
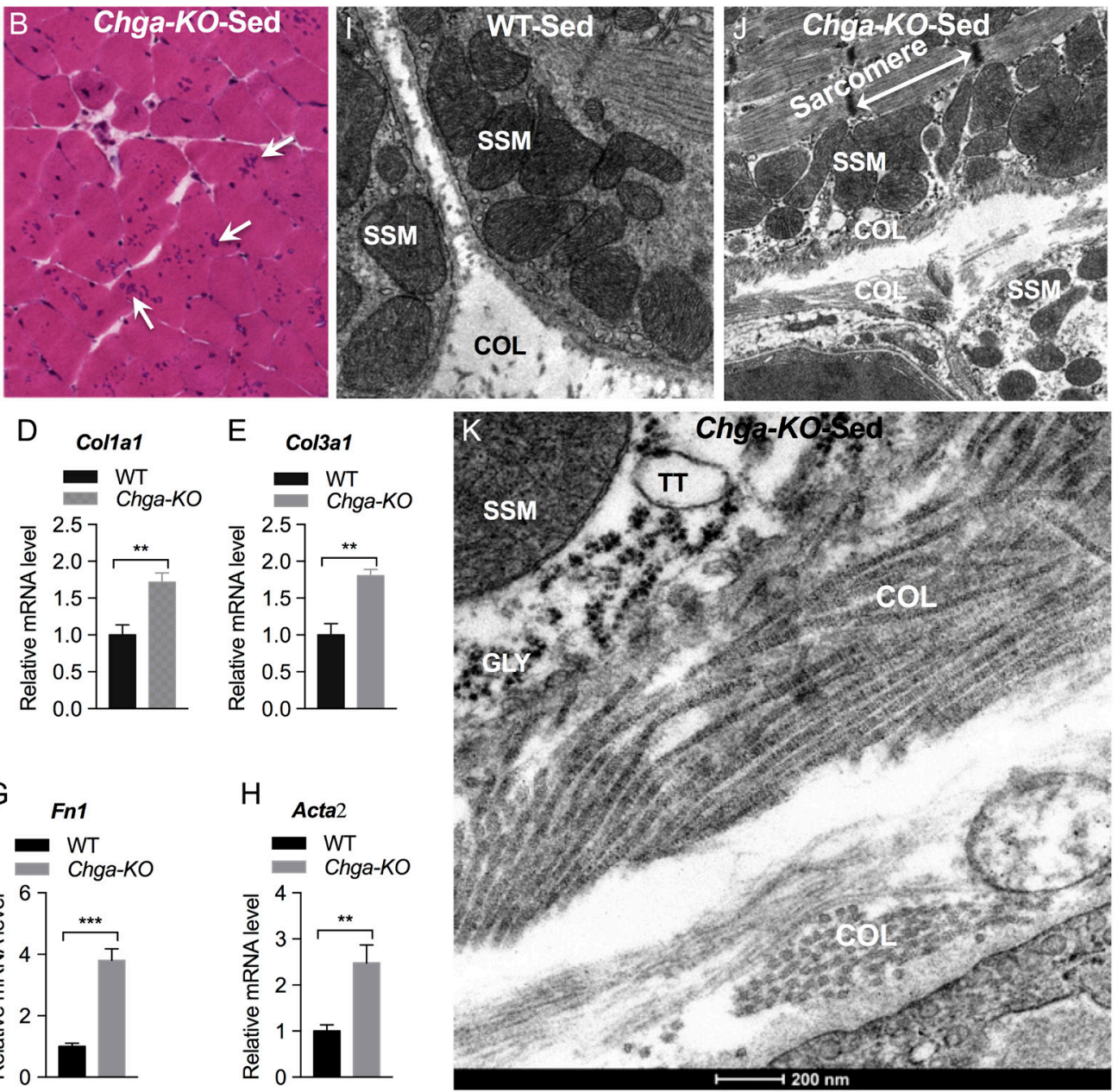

\section{Figure 6}

Increased fibrosis in GAS muscle of sedentary mice. (A and B) Hematoxylin and eosin-stained transverse sections of GAS muscle in sedentary WT and Chga-KO mice. The arrows show dot-like irregular structures in the myofibrillar region. Expression of fibrotic genes: Collagen type I alpha 1 (Co/1a 1) (C and D), collagen type III alpha 1 (Col3a1) (C and E), Lysyl oxidase (Lox) (C and F), fibronectin 1 (Fn1) (C and G), and smooth muscle aortic alpha-actin (Acta2) (C and H). Transmission electron microscope (TEM) micrographs showing accumulation of collagen: Low magnification (2900x) photographs in WT and Chga-KO GAS muscle (I and J). High magnification (23,000x) photographs showing collagen in Chga-KO muscle (K). COL, collagen; GLY, glycogen; SSM, subsarcolemmal mitochondria; TT, T-tubule. A full colour version of this figure is available at http://dx.doi.org/10.1530/JOE-16-0370. http://joe.endocrinology-journals.org
DOI: $10.1530 /$ JOE-16-0370 (c) 2017 Society for Endocrinology Printed in Great Britain
Published by Bioscientifica Ltd 
Chga expression appears to be the lowest in GAS muscle (Fig. $1 \mathrm{H}, \mathrm{I}$ and $\mathrm{J}$ ). We also looked at the expression of other members of the chromogranin/secretogranin protein family (Chgb and $S c g 2$ ), which revealed that multiple granins were detected, with $S c g 2$ being the most highly expressed granin (Fig. 1I, J, K, L, M and N).

\section{Insulin-induced signaling}

Previously, we have shown muscle insulin resistance in Chga-KO mice (Gayen et al. 2009). Hence, we tested whether insulin signaling was impaired in GAS from Chga-KO mice. Insulin caused 2.2- and 1.7-fold increments in AKT (Ser473) phosphorylation in WT mice and Chga-KO mice, respectively (Fig. 2A and $B)$, indicating impaired PI-3Kinase signaling in GAS muscle. Insulin also activates the stress-activated p38MAPK (Somwar et al. 2000), so we evaluated insulin-induced activation of p38MAPK. Insulininduced phosphorylation of $\mathrm{p} 38 \mathrm{~K}$ was also significantly higher in WT mice than Chga-KO mice (2.0- vs 1.5fold, respectively), indicating a similar impairment in MAPK signaling pathway (Fig. 2A and D). The TBC1D1 protein plays an important role in insulin- and exerciseregulated Glut4 translocation (Sakamoto \& Holman
2008, Middelbeek et al. 2013), and AKT phosphorylates TBC1D1 at Thr590 in skeletal muscle (Vichaiwong et al. 2010). Consistent with the AKT data, insulin increased phosphorylation of TBC1D1 at Thr590 2.6-fold in WT mice but not in Chga-KO mice, indicating a defect downstream of AKT in insulin signaling in Chga-KO mice (Fig. 2A and C).

\section{Exercise-induced signaling}

Exercise activates both AMPK (AMP-activated protein kinase), which is sensitive to the AMP/ATP ratio, and AKT in skeletal muscle (Sakamoto et al. 2003, Richter \& Ruderman 2009). Both activated AKT and AMPK phosphorylate TBC1D1 but at distinct residues (Thr590 and Ser700, respectively) (Vichaiwong et al. 2010). Therefore, we assessed whether the impaired muscle function during exercise in Chga-KO mice is associated with impaired AKT or AMPK activation and phosphorylation of TBC1D1. Although exercise caused 1.6-fold increase in phosphorylation of AKT at Ser473, it had no effect on AKT phosphorylation in Chga-KO mice (Fig. 3A and B). In contrast, exercisestimulated phosphorylation of AMPKo at Thr172 site was unchanged (1.5-fold in both WT and Chga-KO)
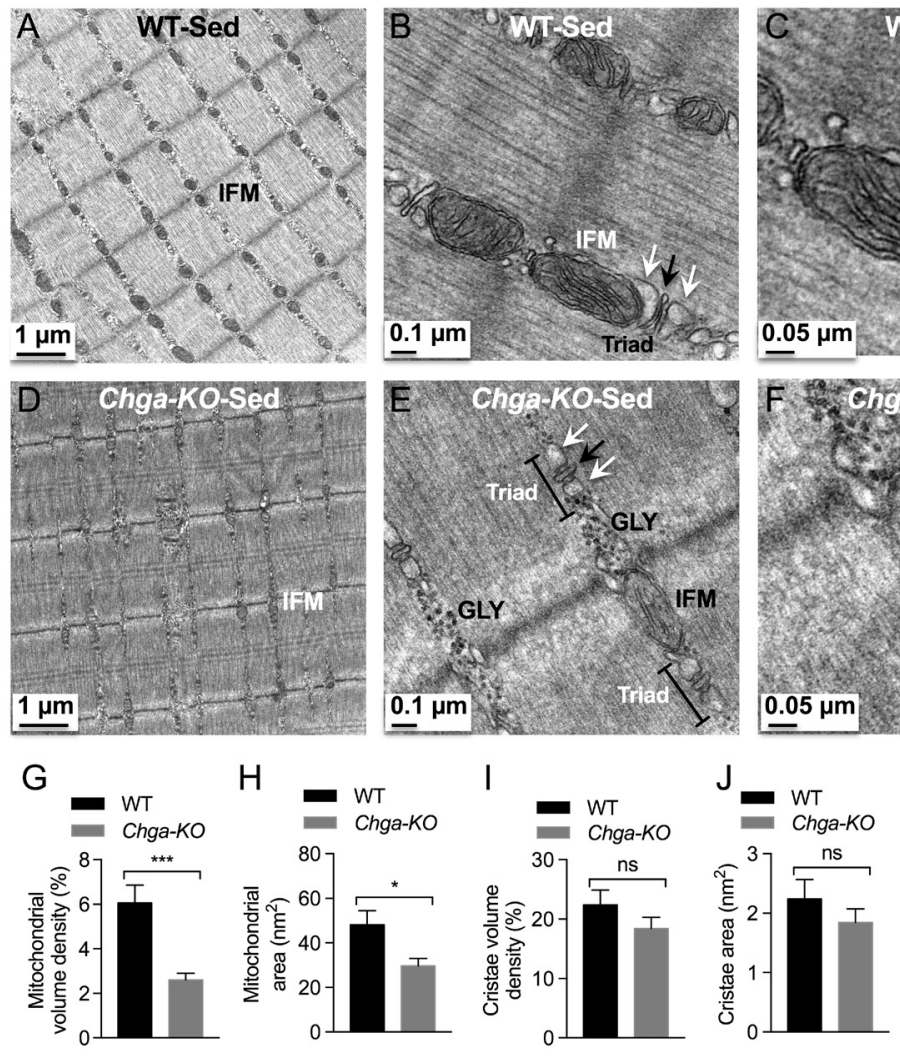

http://joe.endocrinology-journals.org DOI: $10.1530 / J O E-16-0370$
๑ 2017 Society for Endocrinology Printed in Great Britain
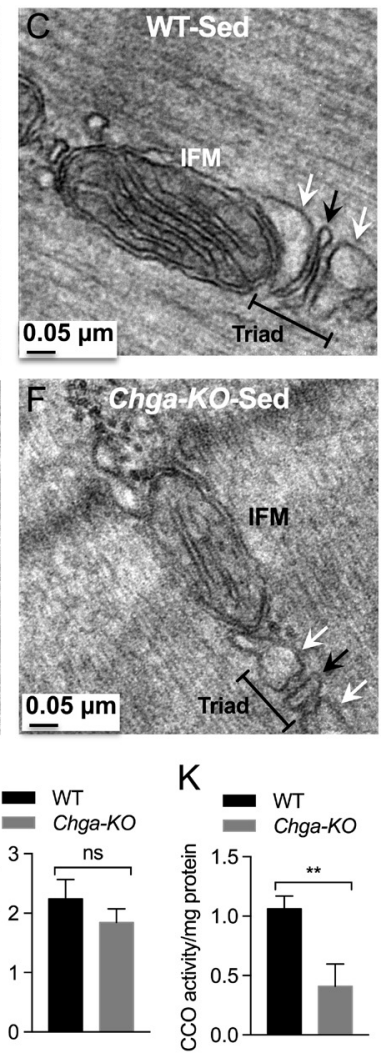

\section{Figure 7}

TEM micrographs in GAS muscle of sedentary mice. Intermyofibrillar mitochondria (IFM) at magnification $2500 \times(A), 15,000 \times(B)$, and 30,000x in WT mice. Note the triad comprising of T-tubule (shown by black arrow) flanked by smooth sarcoplasmic reticulum (shown by white arrow). IMF mitochondria at magnification 2500× (D), $15,000 \times(E)$, and 30,000x (F) in Chga-KO mice. Note glycogen (GLY) granules either in one or both sides of the Z-disc and smaller triad in Chga-KO mice. Morphometric analyses (15 mitochondria from 15 sections per mouse for a total of 4 mice) of TEM micrographs from sedentary WT and Chga-KO mice.

(G) Mitochondrial volume density (\%).

(H) Mitochondrial area $\left(\mathrm{nm}^{2}\right)$. (I) Cristae volume density (\%). (J) Cristae area $\left(\mathrm{nm}^{2}\right)$. (K) Cytochrome $\mathrm{C}$ oxidase (CCO) activity in sedentary WT and Chga-KO mice. 
(Fig. 3A and C). Although exercise-stimulated phosphorylation of TBC1D1 at Thr590 1.4-fold (AKT site) and at Ser700 1.5-fold (AMPK site) in WT muscle, it had no effect on TBC1D1 phosphorylation in muscle from Chga-KO mice. These findings indicate that both AKT-and AMPK-mediated phosphorylation of TBC1D1 is compromised in Chga-KO mice. Exercise also activates p38MAPK in humans (Aronson et al. 1997, Osman et al. 2000) and rats (Goodyear et al. 1996). Here, we found complete abolition of exercise-induced phosphorylation of p38MAPK in Chga-KO-GAS (Fig. 3A and F), suggesting that the adaptation mechanism to exercise-induced stress and damage has been compromised in Chga-KO-GAS.

\section{Glucose and fatty acid uptake and metabolism in response to exercise}

In skeletal muscle, insulin and exercise are the most physiologically relevant stimulators of glucose transport by the translocation of Glut 4 from intracellular depots to the sarcolemma and transverse tubules (Lauritzen et al. 2010). Activated AKT and AMPK phosphorylate TBC1D1 and activate its GTPase activity allowing Glut4 vesicle translocation. Although blood glucose levels were comparable between WT and Chga-KO mice (Fig. 4A), the expression of Glut4 was significantly reduced in Chga-KO GAS muscle (Fig. 4C). Endurance exercise stimulated both uptake of 2DG (by 1.8-fold) and utilization of G6P (by 1.6-fold) in WT mice, but both glucose uptake and utilization of G6P were decreased in the sedentary Chga-KO mice and did not change significantly with exercise (Fig. 4B and D). Decreased G6P content indicates increased glucose utilization. Chga-KO mice displayed decreased plasma triglycerides (Fig. 4E) and dramatically reduced the expression of the fatty acid transporter $C d 36$ (Fig. 4G). Glucose and fatty acids are the main substrates that provide metabolic energy for the contractile activity of muscle. Although glucose uptake and metabolism were increased in WT muscle after endurance exercise, fatty acid uptake and metabolism were decreased (Fig. 4F) consistent with a switch from lipid oxidation to glucose utilization in GAS muscle. Similar to the findings for glucose utilization, sedentary Chga-KO mice showed decreased fatty acid uptake and oxidation, endurance exercise caused a further drop in fatty acid uptake and metabolism (Fig. 4H). Taken together, these findings indicate that GAS muscle in Chga-KO mice shows impaired utilization of both glucose and fatty acids as an energy source.

\section{Expression of genes involved in regeneration and inflammation}

We assessed a panel of muscle progenitor and satellite cell markers in GAS muscle from WT and Chga-KO mice. In sedentary mice, we found increased expression of progenitor cell markers MyoD (4-fold) and Pax3 (3.4-fold) in Chga-KO mice compared to WT mice (Fig. 5A), but no change in satellite marker Myf5 (Relaix et al. 2006, Young \& Wagers 2010, Filareto et al. 2015). Chga-KO mice also showed increased expression of pro-inflammatory genes $\operatorname{Tnf\alpha }$ (1.8-fold), If $n \gamma$ (3.8-fold) and Il6 (7.3-fold) as well as expression of anti-inflammatory gene $I l 10$ (by 5.6-fold) as compared to WT mice (Fig. 5B). It is possible that although the increased expression of MyoD1 and Pax3 may drive the proliferation and differentiation of progenitor cells (Relaix et al. 2006, Young \& Wagers 2010, Filareto et al. 2015), increased expression of Ifn $\gamma$ may inhibit myogenin activity and prevent differentiation (Londhe \& Davie 2011).
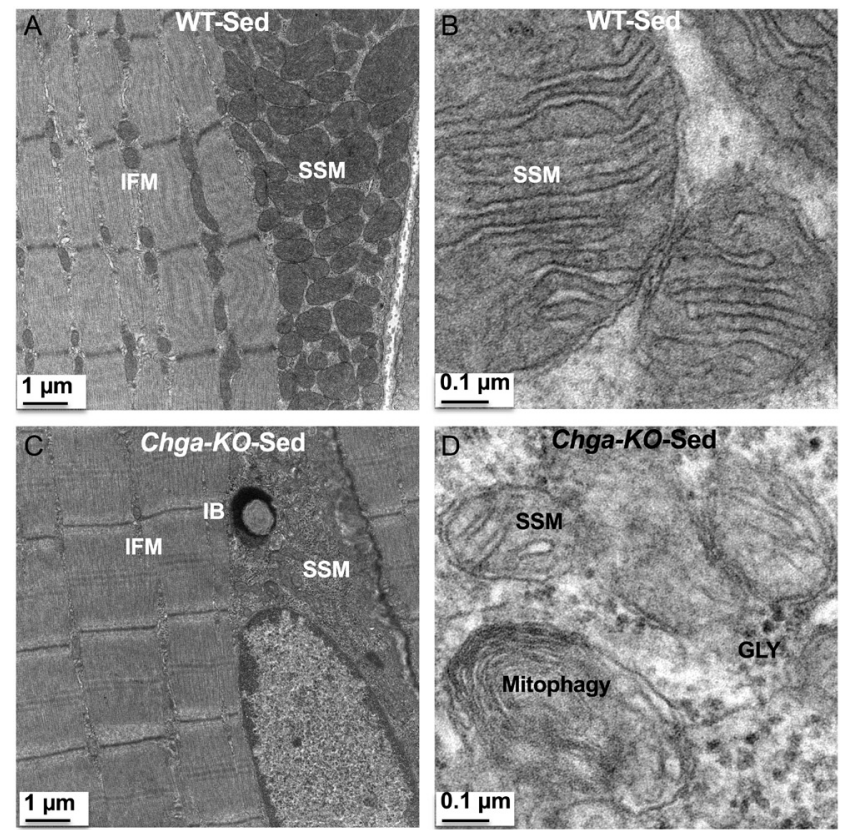

\section{Figure 8}

Subsarcolemmal mitochondria (SSM) in sedentary WT and Chga-KO GAS muscle. (A) SSM and IFM at magnification 2500x in WT mice. (B) SSM at magnification 30,000x in WT mice. Note cristae emerging from the inner mitochondrial membrane. (C) SSM and IFM at magnification 2500x in Chga-KO mice. Note inclusion body in the subsarcolemmal region. (D) SSM at magnification 30,000x in Chga-KO mice. Note mitophagy, fewer cristae and glycogen granules (GLY).

Published by Bioscientifica Ltd. 


\section{Ultrastructural analysis of GAS muscle in sedentary mice}

Hematoxylin/eosin staining of transverse sections of GAS muscle revealed morphological alterations in Chga-KO mice compared to WT (Fig. 6A and B). In particular, the sections from Chga-KO mice showed increased intermyofibrillar fibrosis as shown by the increased expression of collagen type 1 alpha 1 (Col1a1), collagen type III alpha 1 (Col3a1), lysyl oxidase (Lox), fibronectin 1 (Fn1) and smooth muscle alpha-actin (Acta2) (Fig. 6C, D, $\mathrm{E}, \mathrm{F}, \mathrm{G}$ and $\mathrm{H}$ ) and the demonstration of collagen fibers at the ultrastructural level (Fig. 6I, J and K). In addition, histological sections show central nucleation, smaller rounded fibers and unusual irregular clusters of dotted
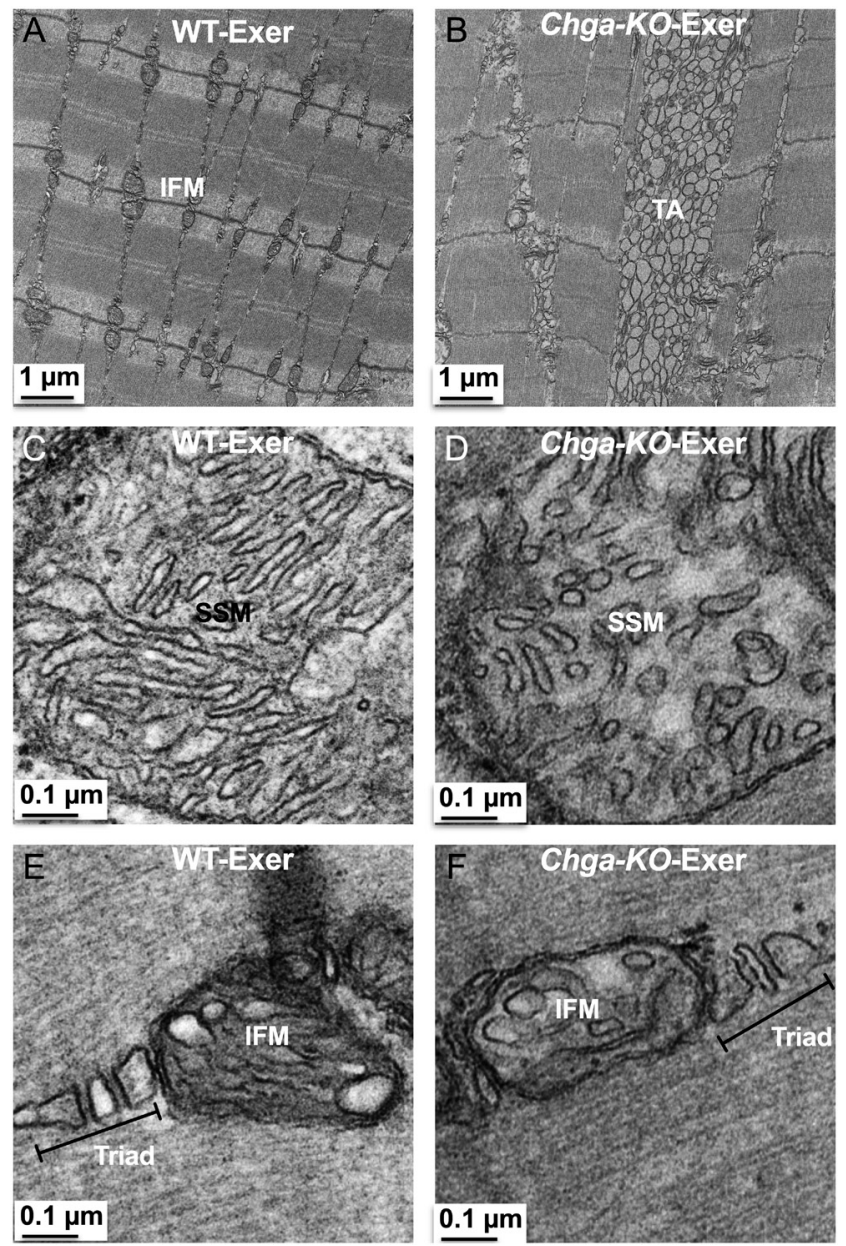

Figure 9

Mitochondria and TA in exercised longitudinally sectioned WT and Chga-KO GAS muscle. (A) IFM at 2500x in WT mice. (B) TA at 2500x in Chga-KO mice. (C) SSM at 30,000 $\times$ with dilated cristae and long cristae in WT mice. (D) SSM at 30,000 $\times$ with round, oval and smaller cristae in Chga-KO mice. (E) IFM at 30,000 $\times$ with dilated cristae and T-tubule in WT mice. (F) IFM at 30,000x with dilated cristae and normal triad. structures in the myofibrillar region suggesting tubular aggregation (Fig. 6A and B). These alterations prompted us to examine those structures at the ultrastructural level.

In WT mice, we observed a mitochondrion in the intermyofibrillar (IMF) region on either side of the Z-disc (perpendicular to the Z-disc) in longitudinal sections (Fig. 7A and B). In addition, we found triads consisting of T-tubules (TT) flanked by smooth sarcoplasmic reticulum (SSR) adjacent to the mitochondria (Fig. 7B and C). In contrast, these IMF structures were disrupted in Chga-KO-GAS with fewer or absent mitochondria and smaller triad structures (Fig. 7D, E and F). In place of these intermyofibrillar mitochondria (IFM), glycogen granules were detected
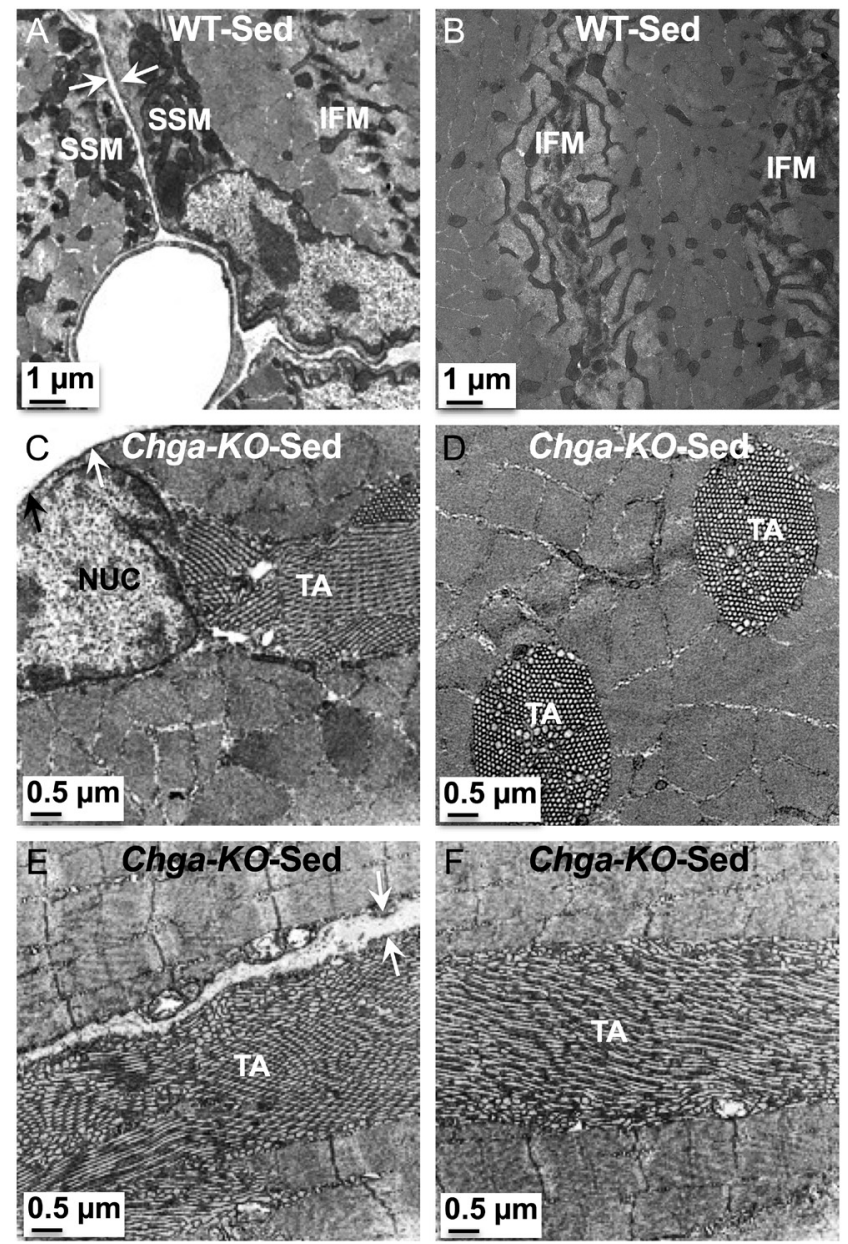

\section{Figure 10}

Tubular aggregates (TAs) in sedentary Chga-KO GAS muscle. (A and B) Transverse sections showing SSM and IFM and the absence of TA in subsarcolemmal and myofibrillar regions. Note elongated IFM. TAs in transverse sections. TA in subsarcolemmal (C) and myofibrillar (D) regions. TAs in longitudinal sections. TA in subsarcolemmal (E) and myofibrillar (F) regions. White arrow points to sarcolemma.

Published by Bioscientifica Ltd 

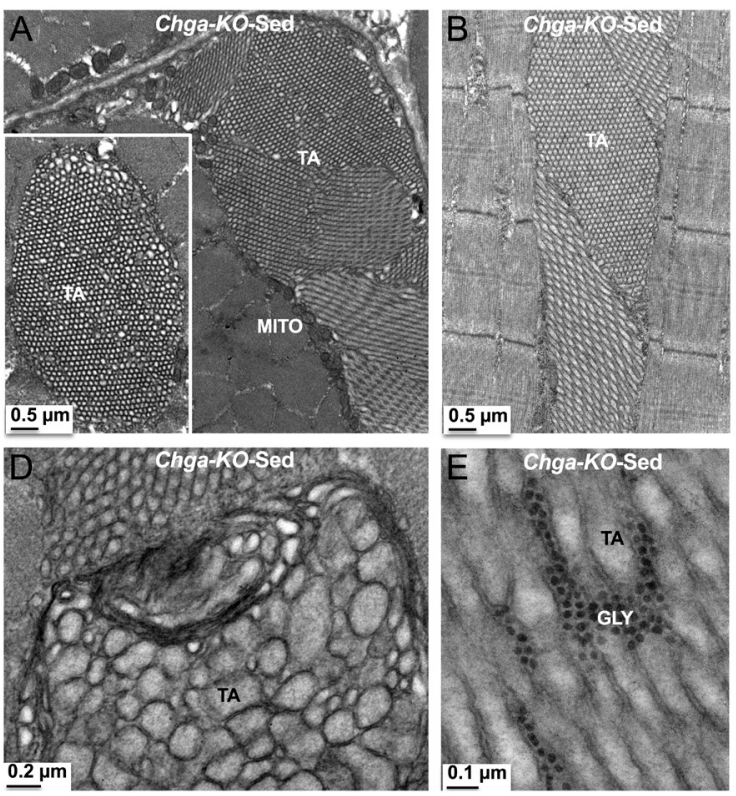
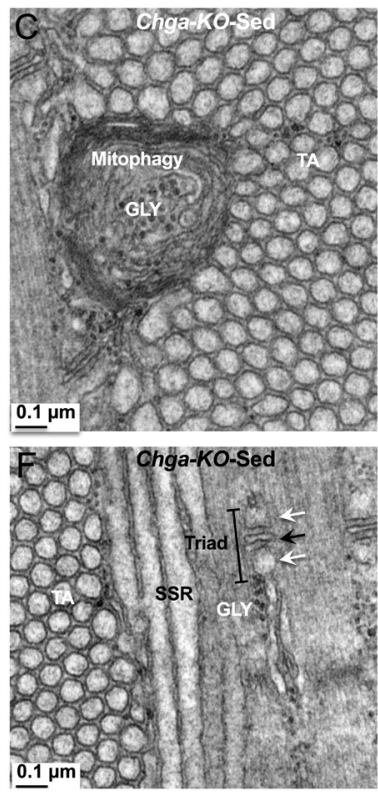

\section{Figure 11}

Tubular aggregates (TAs) in sedentary Chga-KO GAS muscle. (A) Transverse section showing a large aggregate where sub-clusters display different tubule orientation relative to the sarcomere and mitochondria (MITO) in the outer border of TA. The inset shows a honeycomb-like TA. (B) Longitudinal section showing a TA, which runs parallel to the sarcomere. (C) Longitudinal section showing a TA with paracrystalline single-walled tubules of comparable area and a damaged mitochondrion (mitophagy). (D) Longitudinal section showing a $\mathrm{TA}$, where paracrystalline tubules are of different areas. (E) Longitudinal section showing a TA with double-walled tubules and glycogen (GLY) granules in between two tubules. (F) Longitudinal section showing a TA where tubules are cut in the longitudinal, oblique or perpendicular to the sarcomere. Note triad and glycogen granules in the vicinity of TA. Black arrow points to T-tubule and white arrow points to smooth sarcoplasmic reticulum. either on one or both sides of the Z-disc in sedentary Chga-KO-GAS. Morphometric analysis of structures in Chga-KO-GAS indicated decreased mitochondrial density and area (Fig. 7G and H). However, there were no significant changes in cristae density or area for the remaining mitochondria (Fig. 7I and J). Defective mitochondrial function in sedentary Chga-KO-GAS was observed by the decreased cytochrome $\mathrm{C}$ oxidase (CCO) activity compared to WT mice (Fig. 7K). Subsarcolemmal mitochondria (SSM) displayed prominent cristae in WT mice (Fig. 8A and B), but SSM mitochondria were smaller in size and with fewer cristae in Chga-KO mice (Fig. 8C and D). In addition, we observed mitophagy, and inclusion body and glycogen granules in the subsarcolemmal region in Chga-KO mice (Fig. 8C and D).

We also examined the ultrastructure of exercised muscle. IFM in exercised WT mice were enlarged but maintained their localization perpendicular to the Z-disc (Fig. 9A), whereas exercised Chga-KO-muscle showed decreased numbers of mitochondria and increased observation of tubular aggregates (TA) (Fig. 9B). Higher magnification revealed dilated cristae in both the SSM and IFM of WT mice, (Fig. 9C and E) but mitochondria in exercised Chga-KO mice displayed smaller round or ovoid cristae (Fig. 9D and F).

In WT mice, tubular aggregates (TAs) were not detected in the subsarcolemmal as well as myofibrillar regions in transverse sections (Fig. 10A and B). As compared to longitudinal sections, mitochondria in the myofibrillar regions appear elongated and connected in transverse sections (Fig. 10A and B). In contrast to WT mice, TAs were observed in sedentary Chga-KO mice in both transverse (Fig. 10C and D) and longitudinal (Fig. 10E and F) sections. In addition, TAs are detected both in the subsarcolemmal (Fig. 10C and E) and myofibrillar (Fig. 10D and F) regions. TAs are characterized as densely packed aggregates of vesicular or tubular membranes of variable form and size. In transverse sections, the TAs appear as a honeycomb-like structure displaying a paracrystalline order (Figs 10C, D and 11A). In longitudinal sections, the TAs run parallel to the sarcomeres (Figs 10E, $\mathrm{F}$ and 11B). The TAs were either single-walled (Fig. 11C and D) or double-walled empty tubules (Fig. 11E and F) and contain mitophagy structure (Fig. 11C). Glycogen granules were occasionally found between the doublewalled tubules (Fig. 11E). Tubules in large aggregates show sub-clusters with different tubule orientation relative to the sarcomere (Fig. 11A) either longitudinal, oblique or perpendicular within a single section (Fig. 11A, B and F).

\section{Discussion}

The secretory proprotein $\mathrm{CgA}$ is widely expressed in endocrine and neuroendocrine tissues as well as in the central nervous system and is co-released with the resident hormones (Winkler \& Fischer-Colbrie 1992, Montero-Hadjadje et al. 2008, Bartolomucci et al. 2011). Here, we detected CgA expression in GAS muscle and found that its absence, in Chga-KO mice, caused impaired muscle function. Based on the very low mRNA level, yet http://joe.endocrinology-journals.org DOI: $10.1530 / J O E-16-0370$
() 2017 Society for Endocrinology Printed in Great Britain 
strong protein expression, it is possible that the source of processed $\mathrm{CgA}$ is from the axon terminals that innervate the muscle rather than the muscle cell itself. It has been reported that mRNA is transported from the cell body to the axon terminal where it is translated into protein and released exocytotically into the innervating tissue (Kar et al. 2013, Jung et al. 2014, Gervasi et al. 2016). Hence, the effects of $\mathrm{CgA}$ may well be paracrine in origin rather than autocrine. Secretogranin II, another member of the chromogranin/secretogranin protein family, has also been detected in hind limb muscle and cultured myotubes (Egger et al. 2007). Supplementation with CgA in Chga-KO mice restored exercise ability. Together, these data suggest a novel role for endogenous CgA in skeletal muscle function. It should be pointed out that the fulllength CgA protein has recently been implicated in the regulation of myocardial contractility and angiogenesis (Crippa et al. 2013, Pasqua et al. 2013). However, it remains to be established whether CgA activity in muscle function requires local processing to smaller bioactive fragments or not.

The signature defects that characterize the muscle phenotype in Chga-KO mice are (i) lack of exerciseinduced stimulation of pAKT, pTBC1D1 and phosphop38MAPK signaling, (ii) loss of GAS muscle mass, (iii) extensive formation of TA, (iv) disorganized cristae architecture in mitochondria and (v) increased expression of Tnfo and If $r$. We believe that the impaired maximum running speed and endurance in the treadmill exercise in Chga-KO mice are due to the decrease in glucose uptake and glycolysis and defects in glucose oxidation caused by defective mitochondria. In addition, the lack of adaptation to endurance exercise likely results from the impaired activation of stress responses, possibly resulting in deficiency in proliferation and differentiation of myogenic cells. It should be pointed out that Chga-KO mice are unique showing increased insulin sensitivity in the face of persistent hypertension (Mahapatra et al. 2005, Gayen et al. 2009, Biswas et al. 2012, Bandyopadhyay et al. 2015).

Decreased insulin-induced AKT phosphorylation at Ser473 and comparable phosphorylation of TBC1D1 at Thr590 confirm the muscle resistance phenotype that we have reported earlier (Gayen et al. 2009). Fibrosis is increasingly appreciated as a major contributor to metabolic dysregulation in obese humans and type 2 diabetics, and increased expression of collagen was observed in Chga-KO muscle, which may contribute to the insulinresistant state (Sun et al. 2013). Although AMPK signaling in response to exercise was normal in Chga-KO-GAS, it was ineffective at activating TBC1D1 signaling, which correlated with the reduced ability of exercise to stimulate glucose uptake. Activation of p38 MAPK during muscle contraction can stimulate the expression of $P g c 1 \alpha$, Atf 2 and Mef2 and mediate mitochondrial adaptation (Akimoto et al. 2005), and the p38MAPK $\gamma$-PGC1 $\alpha$ pathway is central to the adaptive response to tissue damage in muscle (Pogozelski et al. 2009). So the lack of stimulation of p38MAPK by either insulin or exercise likely prevented the post-exercise adaptation to tissue damage in the Chga-KO mice.

The gene expression pattern in Chga-KO-GAS suggested that mice were attempting to compensate for the impaired muscle function due to the loss of CgA by increasing the proliferation and differentiation of Myodand Pax3-positive progenitor cells (Relaix et al. 2006, Young \& Wagers 2010, Filareto et al. 2015). However, the damaged muscle also triggers an immune response, and the increased expression of Ifny could inhibit myogenin, via the major histocompatibility complex class II transactivator CIITA and MyoD activities and prevent differentiation (Londhe \& Davie 2011, Villalta et al. 2011). Furthermore, the increased expression of IL-6 may have negative effects on glucose uptake in muscle (Kim et al. 2004).

Mitochondria are essential to muscle function as they allow the efficient oxidation of glucose for the generation of ATP for contraction. Although the cristae volume density and cristae area are comparable in mitochondria between WT and Chga-KO mice, the decrease in mitochondrial number, volume density and area point to decreased mitochondrial function. Indeed cytochrome c oxidase (CCO) activity is decreased in Chga-KO muscle. The CCO enzyme complex is found on the inner mitochondrial membrane and serves as the final electron acceptor in mitochondrial electron transport and has been reported to increase after endurance exercise (Samelman et al. 2000). Thus, decreased CCO activity in Chga-KO GAS muscle coupled with decreased endurance performance is consistent with reduced mitochondrial function (Samelman et al. 2000).

Although TAs were first described by Engel in 1964 as granular 'crystal-like' inclusions in skeletal muscle (Engel 1964), the mechanisms underlying the formation of TAs and their functional significance for muscle function has remained elusive (Schubert et al. 2007, Schiaffino 2012). Our findings indicate an inverse association between TAs and exercise performance. TA structures can be generated in vitro by hypoxia in extensor digitorum longus (EDL) muscle or by potassium cyanide (Schiaffino et al. 1977).

Published by Bioscientifica Ltd. 
The detection of ubiquitin and hsp72 in these structures (Martin et al. 1991, Muchowski \& Wacker 2005, Luan et al. 2009), has led to the suggestion that the formation of TAs in skeletal muscle is comparable to the formation of protein aggregates in neurodegenerative diseases, but in these diseases, protein aggregation occurs due to misfolding of proteins (Balch et al. 2008, Douglas \& Dillin 2010). In case of TAs, it was suggested that membranebound misfolded proteins could potentially induce the aggregation of SR membranes to which they are bound by cross-linking, but experimental evidence is lacking (Schiaffino 2012). One of the major functions of CgA is to sort proteins to the regulated secretory pathway (Chanat et al. 1991, Taupenot et al. 2002, Bartolomucci et al. 2011). Although the role of CgA in sorting or folding of membrane proteins is yet to be established, one could speculate such a role based on the observed $\mathrm{pH}$-dependent association of $\mathrm{CgA}$ with secretory vesicle membranes (Yoo 1993). Therefore, lack of CgA could cause misfolding of membrane proteins allowing the formation of TAs.

In conclusion, $\mathrm{CgA}$ deficiency causes a myopathic signature in skeletal muscle displaying extensive formation of TA signifying SR reorganization into multiple longitudinally oriented tubules with SERCA in the membrane and calsequestrin in the lumen. This myopathy is also characterized by muscle energy deficiency and the inability to regenerate after exerciseinduced tissue damage. The net result is impaired performance in treadmill exercise.

\section{Declaration of interest}

The authors declare that there is no conflict of interest that could be perceived as prejudicing the impartiality of the research reported.

\section{Funding}

S K Mahata's personal fund and UCSD Academic Senate Grant (R0091B) supported this work. S Mahata was supported by the Noland Scholarship from Caltech. A P Sinha-Hikim was supported by the Diversity Promoting Institution Drug Abuse Research Program (DIDARP grant (R24DA017298) and the Accelerating Excellence in Translational Science (AXIS) grant (2U54MD007598) from the National Institutes of Health.

\section{Acknowledgements}

Transmission electron microscopy was conducted at the Cellular \& Molecular Medicine Electron Microscopy Core Facility at UCSD.

\section{References}

Aardal S, Helle KB, Elsayed S, Reed RK \& Serck-Hanssen G 1993 Vasostatins, comprising the N-terminal domain of chromogranin A, suppress tension in isolated human blood vessel segments. Journal of Neuroendocrinology 5 405-412. (doi:10.1111/j.1365-2826.1993. tb00501.x)
Akimoto T, Pohnert SC, Li P, Zhang M, Gumbs C, Rosenberg PB, Williams RS \& Yan Z 2005 Exercise stimulates Pgc-1alpha transcription in skeletal muscle through activation of the p38 MAPK pathway. Journal of Biological Chemistry 280 19587-19593. (doi:10.1074/jbc.M408862200)

Angelone T, Quintieri AM, Brar BK, Limchaiyawat PT, Tota B, Mahata SK \& Cerra MC 2008 The antihypertensive chromogranin a peptide catestatin acts as a novel endocrine/paracrine modulator of cardiac inotropism and lusitropism. Endocrinology 149 4780-4793. (doi:10.1210/en.2008-0318)

Armstrong RB, Warren GL \& Warren JA 1991 Mechanisms of exercise-induced muscle fibre injury. Sports Medicine 12 184-207. (doi:10.2165/00007256-199112030-00004)

Aronson D, Violan MA, Dufresne SD, Zangen D, Fielding RA \& Goodyear LJ 1997 Exercise stimulates the mitogen-activated protein kinase pathway in human skeletal muscle. Journal of Clinical Investigation 99 1251-1257. (doi:10.1172/JCI119282)

Balch WE, Morimoto RI, Dillin A \& Kelly JW 2008 Adapting proteostasis for disease intervention. Science 319 916-919. (doi:10.1126/ science.1141448)

Bandyopadhyay GK, Lu M, Avolio E, Siddiqui JA, Gayen JR, Wollam J, Vu CU, Chi NW, O'Connor DT \& Mahata SK 2015 Pancreastatindependent inflammatory signaling mediates obesity-induced insulin resistance. Diabetes 64 104-116. (doi:10.2337/db13-1747)

Banks P, Helle KB \& Mayor D 1969 Evidence for the presence of a chromogranin-like protein in bovine splenic nerve granules. Molecular Pharmacology 5 210-212.

Bartlett SF, Lagercrantz H \& Smith AD 1976 Gel electrophoresis of soluble and insoluble proteins of noradrenergic vesicles from ox splenic nerve: a comparison with proteins of adrenal chromaffin granules. Neuroscience 1 339-344. (doi:10.1016/03064522(76)90061-0)

Bartolomucci A, Possenti R, Mahata SK, Fischer-Colbrie R, Loh YP \& Salton SR 2011 The extended granin family: structure, function, and biomedical implications. Endocrine Reviews 32 755-797. (doi:10.1210/ er.2010-0027)

Bertorini TE, Brumback RA, Kula RW \& Engel WK 1977 Electrophysiologic and histochemical observations in five patients with muscle phosphorylase deficiency (MPD). Transactions of the American Neurological Association 102 141-142.

Biswas N, Gayen J, Mahata M, Su Y, Mahata SK \& O'Connor DT 2012 Novel peptide isomer strategy for stable inhibition of catecholamine release: application to hypertension. Hypertension $601552-1559$. (doi:10.1161/HYPERTENSIONAHA.112.202127)

Boncompagni S, Protasi F \& Franzini-Armstrong C 2012 Sequential stages in the age-dependent gradual formation and accumulation of tubular aggregates in fast twitch muscle fibers: SERCA and calsequestrin involvement. Age 34 27-41. (doi:10.1007/s11357-011-9211-y)

Brumback RA, Susag ME \& Gerst JW 1980 Animal model of human disease: defective skeletal muscle glucose and/or glycogen metabolism. American Journal of Pathology 101 241-244.

Brumback RA, Staton RD \& Susag ME 1981 Exercise-induced pain, stiffness, and tubular aggregation in skeletal muscle. Journal of Neurology, Neurosurgery and Psychiatry 44 250-254. (doi:10.1136/ jnnp.44.3.250)

Chanat E, Pimplikar SW, Stinchcombe JC \& Huttner WB 1991 What the granins tell us about the formation of secretory granules in neuroendocrine cells. Cell Biophysics 19 85-91. (doi:10.1007/ BF02989882)

Colombo B, Curnis F, Foglieni C, Monno A, Arrigoni G \& Corti A 2002 Chromogranin A expression in neoplastic cells affects tumor growth and morphogenesis in mouse models. Cancer Research 62 941-946.

Conboy IM \& Rando TA 2002 The regulation of Notch signaling controls satellite cell activation and cell fate determination in postnatal myogenesis. Developmental Cell 3 397-409. (doi:10.1016/S15345807(02)00254-X)

Published by Bioscientifica Ltd. 
Cornelio F \& Di Donato S 1985 Myopathies due to enzyme deficiencies. Journal of Neurology 232 329-340. (doi:10.1007/BF00313831)

Craig ID \& Allen IV 1980 Tubular aggregates in murine dystrophy heterozygotes. Muscle and Nerve 3 134-140. (doi:10.1002/ mus.880030206)

Crippa L, Bianco M, Colombo B, Gasparri AM, Ferrero E, Loh YP, Curnis F \& Corti A 2013 A new chromogranin A-dependent angiogenic switch activated by thrombin. Blood 121 392-402. (doi:10.1182/blood-201205-430314)

Crosson SM, Khan A, Printen J, Pessin JE \& Saltiel AR 2003 PTG gene deletion causes impaired glycogen synthesis and developmental insulin resistance. Journal of Clinical Investigation 111 1423-1432. (doi:10.1172/JCI17975)

De Potter WP, De Schaepdryver AF \& Smith AD 1970a Release of chromogranin A and dopamine-beta-hydroxylase from adrenergic nerves during nerve stimulation. Acta Physiologica Scandinavica 3578

De Potter WP, Smith AD \& De Schaepdryver AF $1970 b$ Subcellular fractionation of splenic nerve: ATP, chromogranin A and dopamine beta-hydroxylase in noradrenergic vesicles. Tissue and Cell 2 529-546. (doi:10.1016/s0040-8166(70)80029-5)

Douen AG, Ramlal T, Klip A, Young DA, Cartee GD \& Holloszy JO 1989 Exercise-induced increase in glucose transporters in plasma membranes of rat skeletal muscle. Endocrinology 124 449-454. (doi:10.1210/endo-124-1-449)

Douglas PM \& Dillin A 2010 Protein homeostasis and aging in neurodegeneration. Journal of Cell Biology 190 719-729. (doi:10.1083/ jcb.201005144)

Duguez S, Feasson L, Denis C \& Freyssenet D 2002 Mitochondrial biogenesis during skeletal muscle regeneration. American Journal of Physiology: Endocrinology and Metabolism 282 E802-E809. (doi:10.1152/ajpendo.00343.2001)

Egger M, Schgoer W, Beer AG, Jeschke J, Leierer J, Theurl M, Frauscher S, Tepper OM, Niederwanger A, Ritsch A, et al. 2007 Hypoxia up-regulates the angiogenic cytokine secretoneurin via an HIF1alpha- and basic FGF-dependent pathway in muscle cells. FASEB Journal 21 2906-2917. (doi:10.1096/fj.06-7440com)

Engel WK 1964 Mitochondrial aggregates in muscle disease. Journal of Histochemistry and Cytochemistry 12 46-48. (doi:10.1177/12.1.46)

Filareto A, Rinaldi F, Arpke RW, Darabi R, Belanto JJ, Toso EA, Miller AZ, Ervasti JM, McIvor RS, Kyba M, et al. 2015 Pax3-induced expansion enables the genetic correction of dystrophic satellite cells. Skeletal Muscle 5 36. (doi:10.1186/s13395-015-0061-7)

Friden J, Lieber RL \& Thornell LE 1991 Subtle indications of muscle damage following eccentric contractions. Acta Physiologica Scandinavica 142 523-524. (doi:10.1111/j.1748-1716.1991. tb09189.x)

Gayen JR, Saberi M, Schenk S, Biswas N, Vaingankar SM, Cheung WW, Najjar SM, O'Connor DT, Bandyopadhyay G \& Mahata SK 2009 A novel pathway of insulin sensitivity in chromogranin a null mice: a crucial role for pancreastatin in glucose homeostasis. Journal of Biological Chemistry 284 28498-28509. (doi:10.1074/jbc. M109.020636)

Gervasi NM, Scott SS, Aschrafi A, Gale J, Vohra SN, MacGibeny MA, Kar AN, Gioio AE \& Kaplan BB 2016 The local expression and trafficking of tyrosine hydroxylase mRNA in the axons of sympathetic neurons. RNA 22 883-895. (doi:10.1261/rna.053272.115)

Gibala M 2009 Molecular responses to high-intensity interval exercise. Applied Physiology Nutrition and Metabolism 34 428-432. (doi:10.1139/ H09-046)

Goodyear LJ \& Kahn BB 1998 Exercise, glucose transport, and insulin sensitivity. Annual Review of Medicine 49 235-261. (doi:10.1146/ annurev.med.49.1.235)

Goodyear LJ, King PA, Hirshman MF, Thompson CM, Horton ED \& Horton ES 1990 Contractile activity increases plasma membrane glucose transporters in absence of insulin. American Journal of Physiology 258 E667-E672.
Goodyear LJ, Hirshman MF \& Horton ES 1991 $a$ Exercise-induced translocation of skeletal muscle glucose transporters. American Journal of Physiology 261 E795-E799.

Goodyear LJ, Hirshman MF, Smith RJ \& Horton ES $1991 b$ Glucose transporter number, activity, and isoform content in plasma membranes of red and white skeletal muscle. American Journal of Physiology 261 E556-E561.

Goodyear LJ, Chang PY, Sherwood DJ, Dufresne SD \& Moller DE 1996 Effects of exercise and insulin on mitogen-activated protein kinase signaling pathways in rat skeletal muscle. American Journal of Physiology 271 E403-E408.

Helle KB 1966 Some chemical and physical properties of the soluble protein fraction of bovine adrenal chromaffin granules. Molecular Pharmacology 2 298-310.

Hirshman MF, Goodyear LJ, Wardzala LJ, Horton ED \& Horton ES 1990 Identification of an intracellular pool of glucose transporters from basal and insulin-stimulated rat skeletal muscle. Journal of Biological Chemistry 265 987-991.

Jung H, Gkogkas CG, Sonenberg N \& Holt CE 2014 Remote control of gene function by local translation. Cell 157 26-40. (doi:10.1016/j. cell.2014.03.005)

Kar AN, MacGibeny MA, Gervasi NM, Gioio AE \& Kaplan BB 2013 Intra-axonal synthesis of eukaryotic translation initiation factors regulates local protein synthesis and axon growth in rat sympathetic neurons. Journal of Neuroscience 33 7165-7174. (doi:10.1523/ JNEUROSCI.2040-12.2013)

Kim HJ, Higashimori T, Park SY, Choi H, Dong J, Kim YJ, Noh HL, Cho YR, Cline G, Kim YB, et al. 2004 Differential effects of interleukin- 6 and -10 on skeletal muscle and liver insulin action in vivo. Diabetes 53 1060-1067. (doi:10.2337/diabetes.53.4.1060)

Korenyi-Both A, Smith BH \& Baruah JK 1977 McArdle's syndrome. Fine structural changes in muscle. Acta Neuropathologica 40 11-19. (doi:10.1007/BF00688569)

Lauritzen HP, Galbo H, Toyoda T \& Goodyear LJ 2010 Kinetics of contraction-induced GLUT4 translocation in skeletal muscle fibers from living mice. Diabetes 59 2134-2144. (doi:10.2337/db10-0233)

Layzer RB, Rowland LP \& Ranney HM 1967 Muscle phosphofructokinase deficiency. Archives of Neurology 17 512-523. (doi:10.1001/ archneur.1967.00470290066009)

Londhe P \& Davie JK 2011 Gamma interferon modulates myogenesis through the major histocompatibility complex class II transactivator, CIITA. Molecular and Cellular Biology 31 2854-2866. (doi:10.1128/ MCB.05397-11)

Luan X, Chen B, Liu Y, Zheng R, Zhang W \& Yuan Y 2009 Tubular aggregates in paralysis periodica paramyotonica with T704M mutation of SCN4A. Neuropathology 29 579-584. (doi:10.1111/j.14401789.2008.00985.x)

Machida S \& Booth FW 2004 Insulin-like growth factor 1 and muscle growth: implication for satellite cell proliferation. Proceedings of the Nutrition Society 63 337-340. (doi:10.1079/PNS2004354)

Mahapatra NR, O'Connor DT, Vaingankar SM, Hikim AP, Mahata M, Ray S, Staite E, Wu H, Gu Y, Dalton N, et al. 2005 Hypertension from targeted ablation of chromogranin A can be rescued by the human ortholog. Journal of Clinical Investigation 115 1942-1952. (doi:10.1172/JCI24354)

Mahata SK, O'Connor DT, Mahata M, Yoo SH, Taupenot L, Wu H, Gill BM \& Parmer RJ 1997 Novel autocrine feedback control of catecholamine release. A discrete chromogranin A fragment is a noncompetitive nicotinic cholinergic antagonist. Journal of Clinical Investigation $\mathbf{1 0 0}$ 1623-1633. (doi:10.1172/JCI119686)

Mahata SK, Mahapatra NR, Mahata M, Wang TC, Kennedy BP, Ziegler MG \& O'Connor DT 2003 Catecholamine secretory vesicle stimulustranscription coupling in vivo. Demonstration by a novel transgenic promoter/photoprotein reporter and inhibition of secretion and transcription by the chromogranin A fragment catestatin. Journal of Biological Chemistry 278 32058-32067. (doi:10.1074/jbc.M305545200)

Published by Bioscientifica Ltd. 
Martin JE, Mather K, Swash M \& Gray AB 1991 Expression of heat shock protein epitopes in tubular aggregates. Muscle and Nerve 14 219-225. (doi:10.1002/mus.880140304)

Middelbeek RJ, Chambers MA, Tantiwong P, Treebak JT, An D, Hirshman MF, Musi N \& Goodyear LJ 2013 Insulin stimulation regulates AS160 and TBC1D1 phosphorylation sites in human skeletal muscle. Nutrition and Diabetes 3 e74. (doi:10.1038/nutd.2013.13)

Montero-Hadjadje M, Vaingankar S, Elias S, Tostivint H, Mahata SK \& Anouar Y 2008 Chromogranins A and B and secretogranin II: evolutionary and functional aspects. Acta Physiologica 192 309-324. (doi:10.1111/j.1748-1716.2007.01806.x)

Muchowski PJ \& Wacker JL 2005 Modulation of neurodegeneration by molecular chaperones. Nature Reviews Neuroscience 6 11-22. (doi:10.1038/nrn1587)

Osman AA, Pendergrass M, Koval J, Maezono K, Cusi K, Pratipanawatr T \& Mandarino LJ 2000 Regulation of MAP kinase pathway activity in vivo in human skeletal muscle. American Journal of Physiology: Endocrinology and Metabolism 278 E992-E999.

Pasqua T, Corti A, Gentile S, Pochini L, Bianco M, Metz-Boutigue MH, Cerra MC, Tota B \& Angelone T 2013 Full-length human chromogranin-A cardioactivity: myocardial, coronary, and stimulus-induced processing evidence in normotensive and hypertensive male rat hearts. Endocrinology 154 3353-3365. (doi:10.1210/en.2012-2210)

Pasqua T, Mahata S, Bandyopadhyay GK, Biswas A, Perkins GA, Sinha Hikim AP, Goldstein DS, Eiden LE \& Mahata SK 2016 Impact of Chromogranin A deficiency on catecholamine storage, catecholamine granule morphology, and chromaffin cell energy metabolism in vivo. Cell and Tissue Research 363 693-712. (doi:10.1007/s00441-015-2316-3)

Paulsen G, Egner I, Raastad T, Reinholt F, Owe S, Lauritzen F, Brorson SH \& Koskinen S 2013 Inflammatory markers CD11b, CD16, CD66b, CD68, myeloperoxidase and neutrophil elastase in eccentric exercised human skeletal muscles. Histochemistry and Cell Biology 139 691-715. (doi:10.1007/s00418-012-1061-x)

Perrey S \& Rupp T 2009 Altitude-induced changes in muscle contractile properties. High Altitude Medicine and Biology 10 175-182. (doi:10.1089/ham.2008.1093)

Pogozelski AR, Geng T, Li P, Yin X, Lira VA, Zhang M, Chi JT \& Yan Z 2009 p38gamma mitogen-activated protein kinase is a key regulator in skeletal muscle metabolic adaptation in mice. PLoS ONE 4 e7934. (doi:10.1371/journal.pone.0007934)

Ratti S, Curnis F, Longhi R, Colombo B, Gasparri A, Magni F, Manera E, Metz-Boutigue MH \& Corti A 2000 Structure-activity relationships of chromogranin A in cell adhesion. Identification of an adhesion site for fibroblasts and smooth muscle cells. Journal of Biological Chemistry 275 29257-29263. (doi:10.1074/jbc.M003796200)

Relaix F, Montarras D, Zaffran S, Gayraud-Morel B, Rocancourt D, Tajbakhsh S, Mansouri A, Cumano A \& Buckingham M 2006 Pax3 and Pax7 have distinct and overlapping functions in adult muscle progenitor cells. Journal of Cell Biology 172 91-102. (doi:10.1083/ jcb.200508044)

Richter EA \& Ruderman NB 2009 AMPK and the biochemistry of exercise: implications for human health and disease. Biochemical Journal $\mathbf{4 1 8}$ 261-275. (doi:10.1042/BJ20082055)

Sakamoto K \& Holman GD 2008 Emerging role for AS160/TBC1D4 and TBC1D1 in the regulation of GLUT4 traffic. American Journal of Physiology: Endocrinology and Metabolism 295 E29-E37. (doi:10.1152/ ajpcell.00466.2007)

Sakamoto K, Aschenbach WG, Hirshman MF \& Goodyear LJ 2003 Akt signaling in skeletal muscle: regulation by exercise and passive stretch. American Journal of Physiology: Endocrinology and Metabolism 285 E1081-E1088. (doi:10.1152/ajpendo.00228.2003)

Samelman TR, Shiry LJ \& Cameron DF 2000 Endurance training increases the expression of mitochondrial and nuclear encoded cytochrome c oxidase subunits and heat shock proteins in rat skeletal muscle.
European Journal of Applied Physiology 83 22-27. (doi:10.1007/ s004210000241)

Sanchez-Margalet V, Gonzalez-Yanes C, Najib S \& Santos-Alvarez J 2010 Metabolic effects and mechanism of action of the chromogranin A-derived peptide pancreastatin. Regulatory Peptides 161 8-14. (doi:10.1016/j.regpep.2010.02.005)

Schiaffino S 2012 Tubular aggregates in skeletal muscle: just a special type of protein aggregates? Neuromuscular Disorders 22 199-207. (doi:10.1016/j.nmd.2011.10.005)

Schiaffino S \& Mammucari C 2011 Regulation of skeletal muscle growth by the IGF1-Akt/PKB pathway: insights from genetic models. Skeletal Muscle 1 4. (doi:10.1186/2044-5040-1-4)

Schiaffino S, Severin E, Cantini M \& Sartore S 1977 Tubular aggregates induced by anoxia in isolated rat skeletal muscle. Laboratory Investigation 37 223-228. (doi:10.3109/00365517709091486)

Schubert W, Sotgia F, Cohen AW, Capozza F, Bonuccelli G, Bruno C, Minetti C, Bonilla E, Dimauro S \& Lisanti MP 2007 Caveolin-1(-/-)and caveolin-2(-/-)-deficient mice both display numerous skeletal muscle abnormalities, with tubular aggregate formation. American Journal of Pathology 170 316-333. (doi:10.2353/ajpath.2007.060687)

Smith WJ \& Kirshner N 1967 A specific soluble protein from the catecholamine storage vesicles of bovine adrenal medulla. I. Purification and chemical characterization. Molecular Pharmacology 3 52-62.

Smith AD \& Winkler H 1967 Purification and properties of an acidic protein from chromaffin granules of bovine adrenal medulla. Biochemical Journal 103 483-492. (doi:10.1042/bj1030483)

Somogyi P, Hodgson AJ, DePotter RW, Fischer-Colbrie R, Schober M, Winkler H \& Chubb IW 1984 Chromogranin immunoreactivity in the central nervous system. Immunochemical characterisation, distribution and relationship to catecholamine and enkephalin pathways. Brain Research 320 193-230. (doi:10.1016/01650173(84)90007-9)

Somwar R, Perreault M, Kapur S, Taha C, Sweeney G, Ramlal T, Kim DY, Keen J, Cote CH, Klip A, et al. 2000 Activation of p38 mitogen-activated protein kinase alpha and beta by insulin and contraction in rat skeletal muscle: potential role in the stimulation of glucose transport. Diabetes 49 1794-1800. (doi:10.2337/ diabetes.49.11.1794)

Sun K, Tordjman J, Clement K \& Scherer PE 2013 Fibrosis and adipose tissue dysfunction. Cell Metabolism 18 470-477. (doi:10.1016/j. cmet.2013.06.016)

Tarui S, Okuno G, Ikura Y, Tanaka T, Suda M \& Nishikawa M 1965 Phosphofructokinase deficiency in skeletal muscle. A new type of glycogenosis. Biochemical and Biophysical Research Communications 19 517-523. (doi:10.1016/0006-291X(65)90156-7)

Tatemoto K, Efendic S, Mutt V, Makk G, Feistner GJ \& Barchas JD 1986 Pancreastatin, a novel pancreatic peptide that inhibits insulin secretion. Nature 324 476-478. (doi:10.1038/324476a0)

Taupenot L, Harper KL, Mahapatra NR, Parmer RJ, Mahata SK \& O'Connor DT 2002 Identification of a novel sorting determinant for the regulated pathway in the secretory protein chromogranin A. Journal of Cell Science 115 4827-4841. (doi:10.1242/jcs.00140)

Tota B, Angelone T, Mazza R \& Cerra MC 2008 The chromogranin A-derived vasostatins: new players in the endocrine heart. Current Medicinal Chemistry 15 1444-1451. (doi:10.2174/092986708784567 662)

Tota B, Gentile S, Pasqua T, Bassino E, Koshimizu H, Cawley NX, Cerra MC, Loh YP \& Angelone T 2012 The novel chromogranin A-derived serpinin and pyroglutaminated serpinin peptides are positive cardiac beta-adrenergic-like inotropes. FASEB Journal $\mathbf{2 6}$ 2888-2898. (doi:10.1096/fj.11-201111)

Vichaiwong K, Purohit S, An D, Toyoda T, Jessen N, Hirshman MF \& Goodyear LJ 2010 Contraction regulates site-specific phosphorylation of TBC1D1 in skeletal muscle. Biochemical Journal 431 311-320. (doi:10.1042/BJ20101100) 
Villalta SA, Deng B, Rinaldi C, Wehling-Henricks M \& Tidball JG 2011 IFN-gamma promotes muscle damage in the mdx mouse model of Duchenne muscular dystrophy by suppressing M2 macrophage activation and inhibiting muscle cell proliferation. Journal of Immunology 187 5419-5428. (doi:10.4049/ jimmunol.1101267)

Volknandt W, Schober M, Fischer-Colbrie R, Zimmermann H \& Winkler H 1987 Cholinergic nerve terminals in the rat diaphragm are chromogranin A immunoreactive. Neuroscience Letters 81 241-244. (doi:10.1016/0304-3940(87)90389-2)

Wagers AJ \& Conboy IM 2005 Cellular and molecular signatures of muscle regeneration: current concepts and controversies in adult myogenesis. Cell 122 659-667. (doi:10.1016/j. cell.2005.08.021)

Winkler H \& Fischer-Colbrie R 1992 The chromogranins A and B: the first 25 years and future perspectives. Neuroscience 49 497-528. (doi:10.1016/0306-4522(92)90222-N)

Yoo SH 1993 pH-dependent association of chromogranin A with secretory vesicle membrane and a putative membrane binding region of chromogranin A. Biochemistry 32 8213-8219. (doi:10.1021/bi00083a023)

Young AP \& Wagers AJ 2010 Pax3 induces differentiation of juvenile skeletal muscle stem cells without transcriptional upregulation of canonical myogenic regulatory factors. Journal of Cell Science $\mathbf{1 2 3}$ 2632-2639. (doi:10.1242/jcs.061606)

Received in final form 13 October 2016

Accepted 31 October 2016

Accepted Preprint published online 31 October 2016
Published by Bioscientifica Ltd 